\title{
Drift-corrected trends and periodic variations in MIPAS IMK/IAA
} ozone measurements

\author{
E. Eckert ${ }^{1}$, T. von Clarmann 1 , M. Kiefer ${ }^{1}$, G. P. Stiller ${ }^{1}$, S. Lossow ${ }^{1}$, N. Glatthor ${ }^{1}$, D. A. Degenstein ${ }^{2}$, L. Froidevaux ${ }^{3}$, \\ S. Godin-Beekmann ${ }^{4}$, T. Leblanc ${ }^{5}$, S. McDermid ${ }^{5}$, M. Pastel $^{4}$, W. Steinbrecht ${ }^{6}$, D. P. J. Swart ${ }^{7}$, K. A. Walker ${ }^{8}$, and \\ P. F. Bernath ${ }^{9}$ \\ ${ }^{1}$ Karlsruhe Institute of Technology, Institute for Meteorology and Climate Research, Karlsruhe, Germany \\ ${ }^{2}$ Institute of Space and Atmospheric Studies, University of Saskatchewan, Saskatoon, Canada \\ ${ }^{3}$ CalTech/Jet Propulsion Laboratory, Pasadena, California, USA \\ ${ }^{4}$ Laboratoire Atmosphère, Milieux, Observations Spatiales (LATMOS), Institut Pierre Simon Laplace, Université Pierre et \\ Marie Curie, Université Versailles St-Quentin-en-Yvelines, Centre National de la Recherche Scientifique, Paris, France \\ ${ }^{5}$ California Institute of Technology, Jet Propulsion Laboratory, Wrightwood, CA, USA \\ ${ }^{6}$ Meteorological Observatory, Deutscher Wetterdienst, Hohenpeissenberg, Germany \\ ${ }^{7}$ National Institute of Public Health and Environmental Protection, P.O. Box 1, 3720 BA Bilthoven, the Netherlands \\ ${ }^{8}$ Department of Physics, University of Toronto, Ontario, Canada \\ ${ }^{9}$ Department of Chemistry and Biochemistry, Old Dominion University, Norfolk, VA 23529-0126, USA
}

Correspondence to: E. Eckert (ellen.eckert@kit.edu)

Received: 7 June 2013 - Published in Atmos. Chem. Phys. Discuss.: 4 July 2013

Revised: 12 January 2014 - Accepted: 20 January 2014 - Published: 13 March 2014

\begin{abstract}
Drifts, trends and periodic variations were calculated from monthly zonally averaged ozone profiles. The ozone profiles were derived from level- $1 b$ data of the Michelson Interferometer for Passive Atmospheric Sounding (MIPAS) by means of the scientific level-2 processor run by the Karlsruhe Institute of Technology (KIT), Institute for Meteorology and Climate Research (IMK). All trend and drift analyses were performed using a multilinear parametric trend model which includes a linear term, several harmonics with period lengths from 3 to 24 months and the quasi-biennial oscillation (QBO). Drifts at 2-sigma significance level were mainly negative for ozone relative to Aura MLS and Odin OSIRIS and negative or near zero for most of the comparisons to lidar measurements. Lidar stations used here include those at Hohenpeissenberg $\left(47.8^{\circ} \mathrm{N}, 11.0^{\circ} \mathrm{E}\right)$, Lauder $\left(45.0^{\circ} \mathrm{S}, 169.7^{\circ} \mathrm{E}\right)$, Mauna Loa $\left(19.5^{\circ} \mathrm{N}, 155.6^{\circ} \mathrm{W}\right)$, Observatoire Haute Provence $\left(43.9^{\circ} \mathrm{N}\right.$, $\left.5.7^{\circ} \mathrm{E}\right)$ and Table Mountain $\left(34.4^{\circ} \mathrm{N}, 117.7^{\circ} \mathrm{W}\right)$. Drifts against the Atmospheric Chemistry Experiment Fourier Transform Spectrometer (ACE-FTS) were found to be mostly insignificant. The assessed MIPAS ozone trends cover the time period of July 2002 to April 2012 and
\end{abstract}

range from $-0.56 \mathrm{ppmv}^{\mathrm{decade}}{ }^{-1}$ to $+0.48 \mathrm{ppmv}^{-1 e c a d e}{ }^{-1}$ $\left(-0.52 \mathrm{ppmv}_{\mathrm{decade}}^{-1}\right.$ to $+0.47 \mathrm{ppmv}^{- \text {decade }^{-1}}$ when displayed on pressure coordinates) depending on altitude/pressure and latitude. From the empirical drift analyses we conclude that the real ozone trends might be slightly more positive/less negative than those calculated from the MIPAS data, by conceding the possibility of MIPAS having a very small (approximately within -0.3 ppmv decade ${ }^{-1}$ ) negative drift for ozone. This leads to drift-corrected

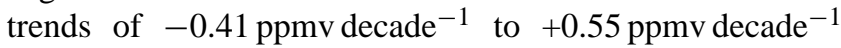
$\left(-0.38\right.$ ppmv decade $^{-1}$ to +0.53 ppmv decade $^{-1}$ when displayed on pressure coordinates) for the time period covered by MIPAS Envisat measurements, with very few negative and large areas of positive trends at mid-latitudes for both hemispheres around and above $30 \mathrm{~km}(\sim 10 \mathrm{hPa})$. Negative trends are found in the tropics around 25 and $35 \mathrm{~km}$ $(\sim 25$ and $5 \mathrm{hPa}$ ), while an area of positive trends is located right above the tropical tropopause. These findings are in good agreement with the recent literature. Differences of the trends compared with the recent literature could be explained by a possible shift of the subtropical mixing barriers. Results for the altitude-latitude distribution of amplitudes of the 
quasi-biennial, annual and the semi-annual oscillation are overall in very good agreement with recent findings.

\section{Introduction}

Stratospheric ozone depletion has been an important issue for more than the past three decades. Although ozone can cause health problems when being present close to the surface in unnaturally large amounts, e.g. downstream of urban areas during warm periods, its presence is very important at higher altitudes. Most of the ozone is located in the stratosphere, where it absorbs ultraviolet light coming from the Sun. Light at these wavelengths can lead to e.g. increased risk of skin cancer; hence the careful monitoring of stratospheric ozone abundances is mandatory.

After Hartley's approximate measurements of the absorption of ozone in the ultraviolet Fabry and Buisson were the first to estimate the vertical thickness of ozone in the atmosphere (Dobson, 1968). Shortly afterwards, during the 1920s, Dobson measured column ozone at Oxford using a Féry spectrograph (Dobson, 1931; Götz et al., 1934). Subsequently further Féry spectrographs were set up at several other locations in Europe. As a second step the measurements were expanded beyond Europe during the late 1920s, including a southern hemispheric site at Christchurch, New Zealand. Over the years, many different instruments and measurement techniques were developed so that nowadays data are collected by ground-based instruments like lidars, airborne observations including instruments carried by airplanes or balloons, and spaceborne limb sounders like MIPAS (Michelson Interferometer for Passive Atmospheric Sounding) Envisat, the Microwave Limb Sounder on the Aura satellite (Aura MLS), the Optical Spectrograph and Infrared Imaging System (Odin OSIRIS) and the Atmospheric Chemistry Experiment Fourier Transform Spectrometer (ACE-FTS). Measurements from the latter satellite instruments are used in the analyses that follow.

All measurements show that the largest abundance of ozone can be found in the stratosphere, forming the ozone layer. This layer protects the Earth's flora and fauna from most of the harmful solar ultraviolet radiation. Molina and Rowland (1974) discovered that some anthropogenically produced chemicals could lead to the depletion of stratospheric ozone. The discovery of the Antarctic ozone hole by Farman et al. (1985) indicated that ozone depletion due to anthropogenic emission of e.g. chlorofluorocarbons (CFC) had the potential of a global threat. These findings led to the restriction of major ozone-depleting substances (ODSs) via the Montreal Protocol in 1987, but since most of these substances are long-lived their amounts continued to increase in the stratosphere until the mid-1990s (WMO, 2011). Consequently a negative global trend in ozone was observed for the same time period, reaching minimum total ozone val- ues during 1996-1997. Even though a decrease of stratospheric ODS concentrations was noted from the mid-1990s on, ozone did not recover consistently. Trends after 1995 were found to be either nonexistent or slightly positive (Steinbrecht et al., 2009a; WMO, 2011).

In this paper, linear variations of ozone calculated from zonal monthly means are shown, which were derived from MIPAS Envisat IMK/IAA level-2 V5H_O3_20, V5R_O3_220 and V5R_O3_221 data. The analyses cover the altitude range from 10 to $44 \mathrm{~km}$ in steps of one kilometre and continue in $2 \mathrm{~km}$ steps up to $50 \mathrm{~km}$. For some cases the analyses were additionally performed on the pressure grid used for Aura MLS and cover a range from 215.44 to $0.68 \mathrm{hPa}$. Beyond this, altitude-latitude distributions of the amplitude of periodic variations with period lengths of 6 (semi-annual oscillation - SAO) and 12 (annual oscillation - AO) months were assessed, as well as the quasi-biennial oscillation (QBO). These results were obtained using MIPAS data from July 2002 to April 2012. MIPAS measurement data exhibit a gap between March 2004 and January 2005, during which no data could be collected by the instrument due to technical problems. This also led to an altered operation mode for the second time period, with different spectral and horizontal resolution and tangent height pattern.

In order to support the trend analyses, drifts are estimated via comparison with several coincident measurements of spaceborne instruments, namely ACE-FTS, Aura MLS and Odin OSIRIS. We also calculated drifts by comparing MIPAS profiles to coincident measurements of the Network for the Detection of Atmospheric Composition Change (NDACC) lidars at Hohenpeissenberg, Mauna Loa, Lauder, Observatoire Haute Provence and Table Mountain. Our conclusions from the drift analyses were used to correct trends derived from the MIPAS data. The instruments used for this study are introduced and characterized in Sect. 2, followed by a detailed description of the method of trend estimation and additional scientific tools in Sect. 3. While the results are presented in Sect. 4, we provide a closing overview in the conclusions (Sect. 5), putting the findings of this work into an overall context and point out possible future work.

\section{Instruments}

\subsection{MIPAS Envisat}

MIPAS was one of the core payload atmospheric chemistry instruments aboard the European satellite Envisat (Fischer et al., 2008). The satellite was launched into a Sunsynchronous polar orbit at approximately $800 \mathrm{~km}$, with $98.55^{\circ}$ inclination, by the European Space Agency (ESA) in March 2002. The instrument setup allows global coverage from pole to pole. Envisat crossed the Equator at approximately 10:00 and 22:00 local time and performed about 14.4 orbits per day. However it ceased sending data on 8 April 
Table 1. Overview of the instruments, important characteristics and time spans used for the drift analyses.

\begin{tabular}{|c|c|c|c|}
\hline Instrument & Version & Vertical resolution & Period used for analyses \\
\hline MIPAS Envisat & V5H_O3_20 & $\sim 2-6 \mathrm{~km}$ & 07/2002-03/2004 \\
\hline MIPAS Envisat & V5R_O3_220 \& V5R_O3_221 & $\sim 2.5-5 \mathrm{~km}$; largest values around $\sim 30-35 \mathrm{~km}$ & $01 / 2005-04 / 2012$ \\
\hline ACE-FTS & v3.0 & $\sim 3-4 \mathrm{~km}$ & 01/2005-09/2009 \\
\hline Aura MLS & $\mathrm{v} 2.2$ & $\sim 2.5-3.0 \mathrm{~km}$ & $01 / 2005-04 / 2012$ \\
\hline Lidar: Hohenpeissenberg & V5.60 MOHP3 & $\sim 1-2 \mathrm{~km}$ below $30 \mathrm{~km}$; degrading to $\sim 9 \mathrm{~km}$ above $40 \mathrm{~km}$ & 07/2002-03/2012 \\
\hline Lidar: Lauder & v8.2 & $\sim 1.8-3 \mathrm{~km}$ up to $30 \mathrm{~km}$; degrading above & 07/2002-06/2011 \\
\hline Lidar: Mauna Loa & v05.15 & $\sim 2-3 \mathrm{~km}$ up to $40 \mathrm{~km}$; degrading above & 07/2002-03/2012 \\
\hline Lidar: Observatoire Haute Provence & $\mathrm{v} 4$ & $\sim 0.6-2.4 \mathrm{~km}$ up to $30 \mathrm{~km}$; degrading to $\sim 6.5 \mathrm{~km}$ at $45 \mathrm{~km}$ & 07/2002-01/2012 \\
\hline Lidar: Table Mountain & LidAna v05.4x to v6.x & $\sim 2-4 \mathrm{~km}$ up to $30 \mathrm{~km}$; degrading above & 07/2002-01/2012 \\
\hline Odin OSIRIS & v5.07 & $\sim 2.2 \mathrm{~km}$ up to about $40 \mathrm{~km}$; degrading above & $07 / 2002-04 / 2012$ \\
\hline
\end{tabular}

2012 and was declared dead shortly afterwards; all in all, MIPAS provided data for a period of about $10 \mathrm{yr}$.

MIPAS is a Fourier transform limb emission spectrometer which measures the signatures of various trace gases within the spectral range of 4.15 to $14.6 \mu \mathrm{m}$. Originally, MIPAS measured one limb scan consisting of 17 tangent altitudes from 6 to $68 \mathrm{~km}$ and about 75 profiles per orbit in its nominal mode, which results in approximately 1000 profiles per day. The spectral resolution of MIPAS during this first time period (2002-2004) was $0.025 \mathrm{~cm}^{-1}$ unapodized $\left(0.035 \mathrm{~cm}^{-1}\right.$ apodized). This period is referred to as the high spectral resolution period. The data version used in this study is associated with this time period is the V5H_O3_20 data set. The retrieval grid width in all MIPAS data versions is $1 \mathrm{~km}$ for altitudes below $44 \mathrm{~km}$ and $2 \mathrm{~km}$ above, independent of the tangent altitudes of the measurements. The vertical resolution of the V5H_O3_20 ozone data product varies between 2 and $6 \mathrm{~km}$. For the second time period we chose to use the combination of the V5R_O3_220 (1541474 profiles) and V5R_O3_221 (331287 profiles) MIPAS ozone product, both of which were derived from version 5.0 and later level-1b data. The V5R_O3_221 data ozone set consistently extends the V5R_O3_220 product after April 2011. These versions of the ozone product are closely linked with version V4O_O3_202 (deduced from version 4.67 level-1b data) as characterized by von Clarmann et al. (2009) and validated by Stiller et al. (2012). The thorough validation of the V5R_O3_220 (and V5R_O3_221) is currently in progress (Laeng et al. (2012) and paper submitted). Differences in the setup from version V4O_O3_202 to both V5R_O3 versions are major changes in level-1b data used (calibrated spectra) and the preceding temperature retrieval of which the results are used for the subsequent ozone retrieval. An empirical continuum emission signal was retrieved up to altitudes of $50 \mathrm{~km}$ instead of only $33 \mathrm{~km}$ in the preceding version. From version V5R_O3_220 to V5R_O3_221 only minor technical changes of the retrieval setup were applied which do not appreciably change the results for ozone in the investigated altitude range. The vertical resolution of the version V5R_O3_220 and V5R_O3_221 data product ranges from about 2.5 to $5 \mathrm{~km}$, exhibiting the worst vertical resolu- tion around 30 to $35 \mathrm{~km}$. Recent investigations of this feature showed that the vertical resolution in this altitude range would be significantly improved by activating microwindows in the MIPAS AB band $\left(1020-1170 \mathrm{~cm}^{-1}\right)$ at and above $33 \mathrm{~km}$ instead of $36 \mathrm{~km}$ and above as performed for the data set used here, at the cost of a higher positive bias, however. The combined data set of V5H_O3_20, V5R_O3_220 and V5R_O3_221 contains 2359706 ozone profiles in total.

\subsection{Aura MLS}

The Microwave Limb Sounder (MLS) is one amongst four instruments currently operating on the Earth Observing System (EOS) Aura satellite, which was launched into a Sunsynchronous, near-polar orbit at about $705 \mathrm{~km}$ by NASA on 15 July 2004. The Aura satellite is dedicated to chemical constituents of the atmosphere, while the other satellites of the EOS program, Aqua and Terra, focus on the hydrological cycle and land processes, respectively (Schoeberl et al., 2006). Aura MLS records microwave emissions in spectral regions centred at approximately 118, 190, 240 and $640 \mathrm{GHz}$ and additionally $2.5 \mathrm{THz}$ (Waters et al., 2006). With a vertical resolution of 2.5 to $3 \mathrm{~km}$ it measures atmospheric constituents in the upper troposphere, stratosphere and mesosphere, while achieving nearly pole-to-pole coverage $\left(82^{\circ} \mathrm{S}\right.$ to $\left.82^{\circ} \mathrm{N}\right)$.

Mainly focusing on tropospheric and stratospheric processes concerning ozone chemistry, Aura MLS provides data on several atmospheric chemical species linked to ozone destruction, including various reservoir gases. With approximately 240 profiles per orbit (nearly 3500 profiles per day) Aura MLS provides a large number of profiles (day and night) and is thus a very good candidate for drift estimation by means of coinciding profiles. In this study the ozone version v2.2 of the Aura MLS data was used. The standard ozone product, which is used in this study, is derived from the $240 \mathrm{GHz}$ region (main line at $235.7 \mathrm{GHz}$ and lines at 243.45 and 244.16 GHz; Froidevaux et al., 2008). This Aura MLS data set is recommended for pressure levels between 215 and $0.02 \mathrm{hPa}$, after necessary data screening is applied (Froidevaux et al., 2008). Since the application of the MIPAS averaging kernel, as described in Sect. 3.3.2, was originally 
performed on the MIPAS altitude grid, we interpolated the Aura MLS data from its pressure grid to an adequate altitude grid using coincident ECMWF temperatures and pressure to calculate pressure-altitude relations. However, using this approach is prone to the risk that the temperatures used for conversion (here from ECMWF analysis) map onto the ozone drift. In order to avoid the related artefact, the drift analysis has in addition also been performed on the Aura MLS pressure grid as explained in Sect. 3.3.3.

\subsection{ACE-FTS}

The Fourier transform spectrometer (FTS) of the Atmospheric Chemistry Experiment (ACE) is one of the two instruments aboard the Canadian satellite SCISAT-1. It was launched into a circular low Earth orbit at approximately $650 \mathrm{~km}$ from an airplane on 12 August 2003, and the routine measurements were started in February 2004. ACE typically measures in the altitude range from 10 to $100 \mathrm{~km}$, depending on the measurement and the strength of the spectral lines, although the high-resolution $\left(0.02 \mathrm{~cm}^{-1}\right)$ infrared FTS can generally start at the cloud tops and reach up to about $150 \mathrm{~km}$. The vertical resolution of the FTS is approximately $3-4 \mathrm{~km}$ (Dupuy et al., 2009). While using a similar wavelength region (2.2 to $13.3 \mu \mathrm{m})$ as MIPAS, ACE-FTS measures in solar occultation. For this study, version v3.0 of the ACE-FTS ozone data was used for comparison. Due to the fact that some of the profiles seemed to show very unrealistic values, the following rejection criteria were applied: first, the criteria provided at the data issue page (https: //databace.scisat.ca/validation/data_issues_table.php), where certain peculiarities are reported, were used to sort out some profiles. In addition, we used only data points of each profile for which all of the following criteria were fulfilled:

- The data value has to be larger than the error.

- The error has to be larger than $1 \%$ of the data value.

Since this approach still left some suspicious profiles in the data sets, we also removed those for which the ozone mixing ratios were outside of the range -10 to $20 \mathrm{ppmv}$. This range was suggested by Dupuy et al. (2009) during the validation of the ACE-FTS ozone product. The profiles were rejected if their values were outside these ranges at any point, which was valid according to the other filter criteria.

\subsection{Odin OSIRIS}

The Optical Spectrograph and InfraRed Imaging System (OSIRIS) is a Canadian instrument aboard the Swedish satellite Odin and has been collecting data since February 2001 (Degenstein et al., 2009). It orbits Sun-synchronously at about $600 \mathrm{~km}$ with northward Equator-crossing time at 18:00 local time and $98^{\circ}$ inclination. Since OSIRIS is an instrument which measures scattered sunlight, measurements are only possible during June, July, August and September (November, December, January and February) in the Northern Hemisphere (Southern Hemisphere) because sunlight is imperative for the instrument's observations. While the optical spectrograph (OS) records spectra of limb-scattered sunlight from 280 to $800 \mathrm{~nm}$ and has a spectral resolution of about $1 \mathrm{~nm}$, the second part of the instrument, the infrared imager (IRI), measures scattered sunlight as well as airglow emissions (Llewellyn et al., 2004). The altitudinal coverage of OSIRIS is generally from 10 to $100 \mathrm{~km}$ and scans from 7 to $70 \mathrm{~km}$ tangent altitude in normal operation mode (Degenstein et al., 2009). In this study we use version v5.07 of the OSIRIS ozone data retrieved by means of the SaskMART multiplicative algebraic reconstruction technique. The retrieved profiles have a vertical resolution of approximately 2.2 up to $40 \mathrm{~km}$, degrading slightly above.

\subsection{Lidars}

All lidar data used in this study were provided by the NDACC community (www.ndacc.org; see also Steinbrecht et al., 2009a, b; McDermid et al., 1990, 1995; Brinksma et al., 2000). These lidars (at Hohenpeissenberg, Lauder, Mauna Loa, Haute Provence and Table Mountain) use the differential absorption lidar (DIAL) Technique (Megie et al., 1977) to derive stratospheric ozone profiles from atmospheric measurements. Light at two different wavelengths is emitted. One wavelength is $308 \mathrm{~nm}$ for all lidars, while the reference wavelength is $353 \mathrm{~nm}$ at Hohenpeissenberg and Lauder and $355 \mathrm{~nm}$ for the other lidars during the investigated time period. Lidar measurements become less reliable with altitude, which is reflected in deteriorating precision from approximately $1 \%$ up to $30 \mathrm{~km}$ through about $2-5 \%$ around $40 \mathrm{~km}$ to up to $25 \%$ at $50 \mathrm{~km}$ (Nair et al., 2012). Most lidars have vertical resolutions of around $2 \mathrm{~km}$ for altitudes below $30 \mathrm{~km}$, which then increases rapidly above. More detailed information about the lidar characteristics and the measurement technique can be found in Nair et al. (2012); Megie et al. (1977). Since the recorded data are provided in terms of number density, ECMWF data were used for conversion to volume mixing ratio.

\section{Methods}

\subsection{Method of trend estimation}

The multilinear parametric trend model used in this study consists of a constant and a linear term, annual and semiannual oscillation terms, as well as several harmonic overtones. Others, like Kirgis et al. (2013), fit the Ozone Depleting Gas Index (ODGI) instead of a linear term and find that the value of total explained variance is increased compared to using a linear term. However, for the time series used here (2002-2012) the ODGI does not differ noticeably from the linear term, which justifies using a simple linear term here. 


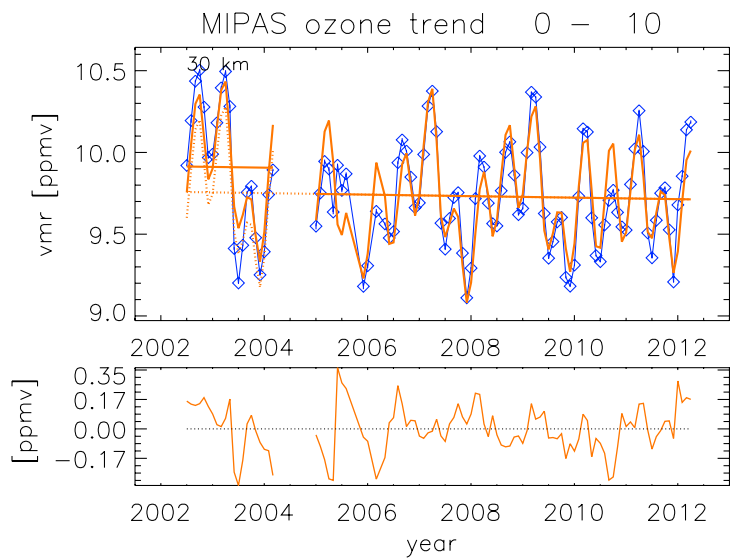

Fig. 1. Trend fit for 0 to $10^{\circ} \mathrm{N}$, showing the monthly mean data (blue diamonds), the calculated fit and the related trend (orange lines) for MIPAS ozone measurements at $30 \mathrm{~km}$. The dotted orange line represents the linear component of the regression function for times affected by bias correction. The bottom panel shows the residual of the fit and the data points.

The QBO was implemented using the Singapore winds at 30 and $50 \mathrm{hPa}$ as a proxy, which are approximately phase-shifted by a quarter period and can thus be treated equivalently to sine and cosine functions of the same period length. Equation (1) is the basic function applied here, similar to Stiller et al. (2012).

$$
\begin{aligned}
\hat{y}(x)=a+b x+c_{1} \mathrm{qbo}_{1}+d_{1} \mathrm{qbo}_{2} & \\
& +\sum_{n=2}^{m}\left(c_{n} \sin \frac{2 \pi x}{l_{n}}+d_{n} \cos \frac{2 \pi x}{l_{n}}\right)
\end{aligned}
$$

Here $x$ is the time, whereas $\mathrm{qbo}_{1}$ and $\mathrm{qbo}_{2}$ refer to the Singapore winds at 30 and $50 \mathrm{hPa}$. The sum comprises 8 sine and cosine functions with the period length $l_{n}$, including the annual and semi-annual oscillation as well as 6 overtones with period lengths of 3, 4, 8, 9, 18 and 24 months. $a$ and $b$ represent the constant term and the slope of the fit, respectively. $c_{n}$ and $d_{n}$ are parameters which have to be found to fit amplitude and phase of the oscillations. The method is based on a concept introduced by von Clarmann et al. (2010) in order to estimate trends of combined data sets which have a potential bias. By using the full covariance matrix when minimizing the cost function (cf. von Clarmann et al., 2010) an arbitrary bias can be accounted for during the regression process and thus makes the model resistant to such biases. The scheme is equivalent to fitting the trends in each data subset individually and ignoring any jump between the subsets. The final trend then corresponds to a weighted mean of the trends of each subset. Coefficients associated with periodic and quasiperiodic variations refer to the entire data set.

In order to account for the autocorrelative nature of the atmosphere and to get realistic error estimates, the autocorrelations among the data points were considered in the co-

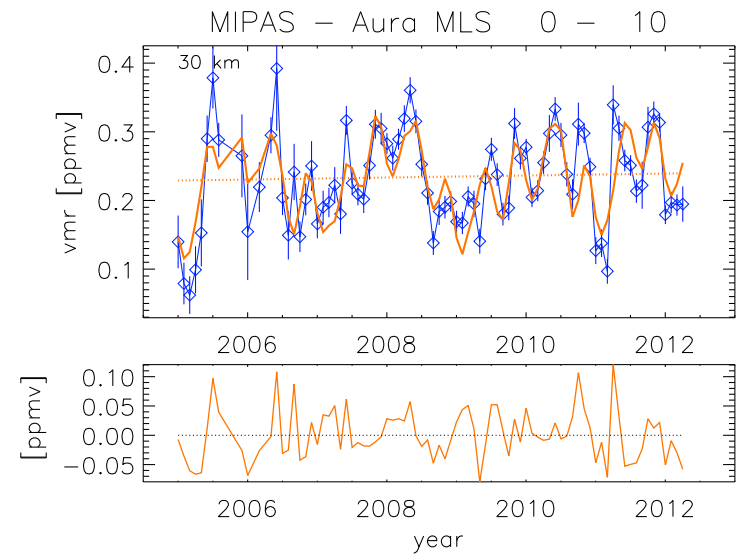

Fig. 2. Trend fit for 0 to $10^{\circ} \mathrm{N}$, showing the monthly mean data (blue diamonds), the calculated fit and the related trend (orange lines) for the differences in the ozone measurements of MIPAS and Aura MLS at $30 \mathrm{~km}$. The first subset of data is missing in the plot compared to Fig. 1 because Aura MLS and MIPAS have no overlap time within the first period of the MIPAS mission (cf. Table 1). The bottom panel shows the residual of the fit and the data points.

variance matrix of the data set, and a model error component was assessed iteratively and added to the covariance matrix such that $\chi^{2}$ of the fit approaches unity. The parameters $a$, $b, c_{n}$ and $d_{n}$ of Eq. (1) were fitted to zonal monthly means of $10^{\circ}$ latitude bands of the MIPAS ozone time series covering 1 July 2002 to 8 April 2012 to assess the linear variation during that period. An example of the fit is shown in Fig. 1, showing the ozone monthly means as well as the fit and linear variation at 0 to $10^{\circ} \mathrm{N}$ and $30 \mathrm{~km}$ altitude. The bias between the two data blocks is quite obvious and it is reasonably accounted for during the fit process. A semi-annual oscillation and a QBO signal can also be identified in the data, which are satisfactorily reproduced by the fit.

Before analysing derived trends, a potential drift in MIPAS ozone data must be identified and accounted for. To estimate the drifts against other instruments, the difference of MIPAS minus the reference instrument was calculated for each data point and the related time series were fitted by the same method as just introduced. The linear term of the variation of these differences is the drift.

\subsection{Drifts}

In our definition, drifts are trend-like artificial linear variations of a signal due to less-than-perfect instrument stability. In order to assess a clean natural trend from the measurements, possible drifts are analysed in a preceding step. This is realized by calculating the difference of the MIPAS measurement and that of another instrument at every valid altitude grid point of each coinciding profile pair, establishing monthly means of these differences and applying the trend method as introduced in Sect. 3.1. Figure 2 shows an example 


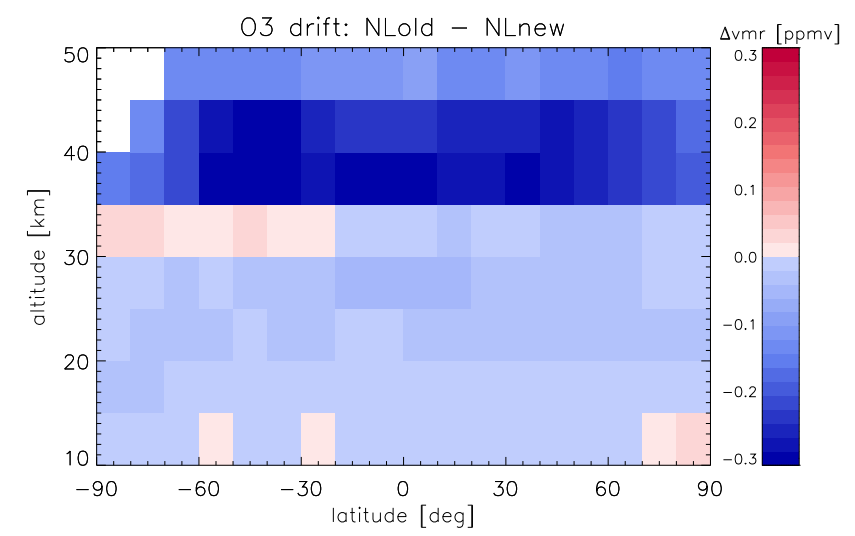

Fig. 3. Altitude-latitude cross-section of absolute drifts resulting from nonlinearity correction. On the basis of a limited number of spectra, ozone analyses based on spectra generated with a timedependent nonlinearity correction are compared to those of a standard nonlinearity correction. The linear component of the temporal development is shown.

of the fit for the differences of Aura MLS and MIPAS. As can be seen here, there are still some oscillations in the differences, which we first expected to cancel out. When we discovered that this assumption was not justified, we decided to use the full multilinear parametric regression model for drift estimation as well, including the whole set of oscillations, instead of just using a linear and a constant term. This is to account for possible dependence of the differences on the atmospheric state.

To improve comparability with e.g. Nair et al. (2012), we also assessed relative drifts by using the relative difference $\left(\mathrm{vmr}_{\mathrm{rel}}\right)$ of each coinciding profile pair consistently with their paper as follows

$$
\begin{aligned}
\mathrm{vmr}_{\text {rel }} & =\frac{\mathrm{vmr}_{\mathrm{M}}-\mathrm{vmr}_{\mathrm{RF}}}{\mathrm{vmr}_{\mathrm{RF}}} \cdot 100 \% \\
& =A \cdot 100 \% .
\end{aligned}
$$

$v r_{M}$ and $v r_{R F}$ are the volume mixing ratios of MIPAS and the reference instrument, respectively. The respective error was estimated accounting for Gaussian error propagation and with respect to Eq. (2).

\subsection{Expected MIPAS drifts}

Recent studies (Kiefer et al., 2013) have raised doubts about the stability of the MIPAS instrument. During the calibration of the spectra, a correction accounting for the nonlinearity of the detector is performed. The coefficients of the nonlinearity correction function were determined prior to the launch of Envistat, but it is believed that ageing makes the detectors more linear and the preflight coefficients might no longer be valid for later MIPAS measurements. The drift possibly introduced by this detector ageing effect is shown in Fig. 3.
The expected artificial drift of ozone due to detector ageing has been the subject of a sensitivity study and is largest above 35 to $40 \mathrm{~km}$. Preliminary results show drifts down to maximum values of -0.3 ppmv decade ${ }^{-1}$ for ozone. The drifts are far smaller than -0.3 ppmv decade ${ }^{-1}$ at lower altitudes and seem to become slightly more negative with altitude. At shorter wavelengths, a larger ageing effect is predicted. This explains the sudden increase of the effect above $35 \mathrm{~km}$. In the data version used, ozone lines of the MIPAS $\mathrm{AB}$ band $\left(1120-1170 \mathrm{~cm}^{-1}\right)$ were used in addition to the $\mathrm{A}$ band $\left(685-970 \mathrm{~cm}^{-1}\right)$ above $33 \mathrm{~km}$, while below only lines from the A band were used.

\subsubsection{Coincidence criteria}

To account for varying data coverage, two different coincidence criteria were used, depending on the availability of data from the respective instrument. For instruments with dense data coverage, measurements which are closer than $250 \mathrm{~km}$ radial spatial distance and $6 \mathrm{~h}$ temporal difference to the MIPAS measurements are taken into account. Weaker criteria of $1000 \mathrm{~km}$ and $24 \mathrm{~h}$ were applied to instruments with sparser coverage and/or fewer measurements to still obtain a sufficiently large number of measurements to compare in the drift analyses. In both cases the distance is calculated relative to the nominal geolocation of the MIPAS profile, which is the tangent point of the $30 \mathrm{~km}$ tangent altitude limb view. Table 2 summarizes these criteria for the different instruments and lists the total number of profiles which matched these criteria. For some instruments which originally cover the whole MIPAS mission period we additionally performed the analysis for a reduced time series, meaning that we only took coincidences of the second MIPAS period into account. This was done in order to assure that the results exhibit only minor changes when the first MIPAS period is omitted due to lack of data, e.g. for instruments like Aura MLS or ACE-FTS.

In cases with more than one measurement fulfilling the coincidence criteria, only the closest profile was chosen. This was done by normalizing the distance and time criteria as shown in Eq. (3), such that the pair with the lowest $C_{\text {comb }}$ value is considered to be the best coincidence.

$C_{\text {comb }}=\left(\frac{d}{d_{\max }}\right)^{2}+\left(\frac{t}{t_{\max }}\right)^{2}$,

where $d$ is the spatial distance between the two profiles, $d_{\max }$ is the maximum allowed distance, $t$ is the time difference between the profiles and $t_{\max }$ is the maximum allowed time difference. In the case of two MIPAS profiles matching the same profile of the other instrument a selection process was undertaken such that the loss of profiles pairs was minimized and the entirety of the pairs fulfilled the criteria best. 
Table 2. Summary of coincidence criteria and the total number of coinciding profiles (reduced time periods - January 2005 to April 2012 - in parenthesis) for the reference instruments with MIPAS, showing the maximal time and spatial distance allowed between the measurements.

\begin{tabular}{lccc}
\hline Instrument & Time criteria [hours] & Distance criteria $[\mathrm{km}]$ & Number of coinciding profiles \\
\hline ACE-FTS & 24 & 1000 & 14190 \\
Aura MLS & 6 & 250 & 401251 \\
Lidar: Hohenpeissenberg (2005-2012) & 24 & 1000 & $652(509)$ \\
Lidar: Lauder & 24 & 1000 & 243 \\
Lidar: Mauna Loa (2005-2012) & 24 & 1000 & $693(503)$ \\
Lidar: Observatoire Haute Provence & 24 & 1000 & 753 \\
Lidar: Table Mountain & 24 & 1000 & 539 \\
Odin OSIRIS (2005-2012) & 6 & 250 & $109820(94274)$ \\
\hline
\end{tabular}

\subsubsection{Application of the MIPAS averaging kernel: on an altitude grid}

In most cases the vertical resolution of the reference instrument was better than that of MIPAS in certain altitude regions. For the lidars this region is rather the lower end of the profile. Their vertical resolution is certainly not better than that of MIPAS above $40 \mathrm{~km}$, but as already mentioned measurements above approximately this altitude should be treated with care. The reason for applying the MIPAS averaging kernels is primarily the vertical resolution peak around 30 to $35 \mathrm{~km}$ in version V5R_O3_220 and V5R_O3_221 of MIPAS data from the second time period of the MIPAS mission. In the case of ACE-FTS the worst-case assumption on the vertical resolution, based on the field of view, is about $3-4 \mathrm{~km}$, which is very similar to that of MIPAS. Sensitivity studies showed that application of the MIPAS averaging kernels to ACE-FTS profiles does not exhibit any major differences compared to ACE-FTS profiles to which no averaging kernels were applied. Thus, for all instruments except ACEFTS the MIPAS averaging kernel was applied according to Eq. (4).

$\tilde{\boldsymbol{x}}_{\mathrm{fM}}=\mathbf{A}_{\mathrm{MIPAS}} \mathbf{V} \boldsymbol{x}_{\mathrm{f}}+\left(\mathbf{I}-\mathbf{A}_{\mathrm{MIPAS}}\right) \boldsymbol{x}_{\mathrm{a}}$

In this equation, $\boldsymbol{x}_{\mathrm{f}}$ is the initially finer profile (e.g. that of Aura MLS). $\tilde{\boldsymbol{x}}_{\mathrm{fM}}$ is that profile transferred to the MIPAS grid under consideration of the MIPAS averaging kernel $\mathbf{A}_{\text {MIPAS. }}$ $\mathbf{I}$ is unity and $\boldsymbol{x}_{\mathrm{a}}$ is the a priori profile used for MIPAS. $\mathbf{V}$ is a transformation matrix relating the fine profile $\boldsymbol{x}_{\mathrm{f}}$ to the coarser grid. It is inferred as follows (cf., e.g. Rodgers, 2000): let $\mathbf{W}$ be an interpolation matrix which transforms a profile originally sampled on a coarse grid onto a finer grid. The transformation from the fine to the coarse grid then uses the transformation matrix $\mathbf{V}=\left(\mathbf{W}^{T} \mathbf{W}\right)^{-1} \mathbf{W}^{T}$.

In the case of ozone a zero a priori profile is used for the MIPAS retrievals, simplifying Eq. (4) to

$\tilde{\boldsymbol{x}}_{\mathrm{fM}, \mathrm{O}_{3}}=\mathbf{A}_{\mathrm{MIPAS}, \mathrm{O}_{3}} \mathbf{V} \boldsymbol{x}_{\mathrm{f}, \mathrm{O}_{3}}$.

More detailed information on the methodology may be found in Stiller et al. (2012).

\subsubsection{Application of the MIPAS averaging kernel: on a pressure grid}

As mentioned above, the conversion of ozone profiles from a pressure grid to an altitude grid relies on ECMWF temperatures which might have a drift in themselves. This would cause an artificial drift in ozone at a given altitude. In order to avoid related problems, for instruments whose native altitude coordinate is pressure (MLS, ACE-FTS), the drift analysis has also been performed on pressure coordinates. Even for MIPAS, whose profiles are usually reported on an altitude grid, the representation on a pressure grid is more robust, since the MIPAS altitudes are based on the hydrostatic approximation involving one ECMWF data triple (altitude, pressure, temperature) per profile. While the altitude resolution of MIPAS and ACE-FTS ozone profiles is comparable over a wide altitude range, a direct comparison is justified (cf. Sect. 3.3.2). Aura MLS ozone profiles, however, have a finer altitude resolution than those of MIPAS, and thus have to be smoothed using the MIPAS averaging kernels. These are provided on an altitude grid; but for all MIPAS altitude grid points, pressure values are also available. We use the following procedure: MLS ozone profiles are interpolated onto the MIPAS pressure grid, for which corresponding altitudes are available. There the MIPAS averaging kernel is applied. The result is transformed back to the Aura MLS pressure grid. This step is necessary because the drift analysis is only meaningful on a fixed grid while the MIPAS pressure grid (contrarily to its altitude grid) varies from profile to profile. For this purpose we need both transformation matrices.

Similar to the previous section, transformation matrices are needed, where the subscript $p$ indicates that the matrices refer to the pressure grid. $\mathbf{W}_{\mathrm{p}}$ performs the transformation from the Aura MLS pressure grid to the MIPAS pressure grid, while the reverse transformation is performed using the matrix $\mathbf{V}_{\mathrm{p}}=\left(\mathbf{W}_{\mathrm{p}}^{T} \mathbf{W}_{\mathrm{p}}\right)^{-1} \mathbf{W}_{\mathrm{p}}^{T}$. The latter transforms the finer sampled MIPAS profile to the coarser Aura MLS grid. The MIPAS profile can be represented as (cf. Rodgers, 2000)

$\hat{\boldsymbol{x}}_{\text {MIPAS }}=\mathbf{A}_{\text {MIPAS }} \boldsymbol{x}_{\text {true }}+\varepsilon_{\text {MIPAS }}$ 
where $\boldsymbol{x}_{\text {true }}$ is the true state of the atmosphere and $\varepsilon_{\text {MIPAS }}$ is the measurement error. Using the transformations introduced above, the MIPAS profile on the Aura MLS pressure grid can be written as

$\mathbf{V}_{\mathrm{p}} \hat{\boldsymbol{x}}_{\text {MIPAS }}=\mathbf{V}_{\mathrm{p}} \mathbf{A}_{\text {MIPAS }} \boldsymbol{x}_{\text {true }}+\mathbf{V}_{\mathrm{p}} \varepsilon_{\text {MIPAS }}$.

We use Aura MLS as a reference instrument and replace $\boldsymbol{x}_{\text {true }}$ with the Aura MLS profile transformed to the MIPAS grid:

$\boldsymbol{x}_{\text {MLS }}{ }_{\text {MIPAS }}=\mathbf{W}_{\mathrm{p}} \boldsymbol{x}_{\text {MLS }}$.

Since MLS is not an ideal instrument either, we replace $\varepsilon_{\text {MIPAS }}$ by the combined error of the two instruments, which leads to

$\mathbf{V}_{\mathrm{p}} \hat{\boldsymbol{x}}_{\text {MIPAS }}=\mathbf{V}_{\mathrm{p}} \mathbf{A}_{\text {MIPAS }} \mathbf{W}_{\mathrm{p}} \boldsymbol{x}_{\text {MLS }}+\mathbf{V}_{\mathrm{p}} \varepsilon_{\text {combined }}$.

Solving this equation for $\mathbf{V}_{\mathrm{p}} \varepsilon_{\text {combined }}$ gives

$\mathbf{V}_{\mathrm{p}} \varepsilon_{\text {combined }}=\mathbf{V}_{\mathrm{p}} \hat{\boldsymbol{x}}_{\text {MIPAS }}-\mathbf{V}_{\mathrm{p}} \mathbf{A}_{\text {MIPAS }} \mathbf{W}_{\mathrm{p}} \hat{\boldsymbol{x}}_{\text {MLS }}$,

where $\mathbf{V}_{\mathrm{p}} \varepsilon_{\text {combined }}$ is the difference profile of the MIPAS and the Aura MLS ozone profile represented on the Aura MLS pressure grid. The linear component of temporal regression of these differences $\frac{d \overline{\mathbf{V}_{\mathrm{p}} \varepsilon_{\text {combined }}}}{\mathrm{d} t}$ is what we call a drift.

\subsection{Drift-corrected trend}

Since we were interested in how the drift would influence the MIPAS ozone trend, we calculated a so-called drift-corrected trend $b_{\text {corrected }}$ (Eq. 11).

$b_{\text {corrected }}=b_{\text {MIPAS }}-b_{\text {Drift,MIPASvsREF }}$

For this purpose we used the drift estimates and calculated the difference of the MIPAS trend $b_{\text {MIPAS }}$ and the drift versus the reference instrument $b_{\text {Drift,MIPASvsREF for every altitude- }}$ latitude grid point. The associated error was simply calculated as the combined error of the MIPAS trend and the drift established in comparison to the respective instrument, both of which were assessed within the respective regression process. Here we assume the difference to be caused by a MIPAS drift to a large extent, not by a possible drift of the other instrument for reasons discussed in Sect. 3.3. The resulting errors can be considered as a conservative estimate, because we did not account for possible correlations between the single instrument errors. If these errors were treated as positively correlated to some extent, the resulting error would decrease. Not expecting any correlation is justified here for the following reasoning: we assume that natural variability should mostly be cancelled out by calculating differences, which is the main contributor to the basic errors. Even though this is not entirely true, as shown in Sect. 3.2, this approximation is valid to a good extent, since the oscillations in the differences are considerably smaller than those in the time series of the measurements themselves. In addition, the data sets used for drift estimation are at least six times smaller than the data set used for trend estimation (MIPAS), because only coinciding measurements are considered.

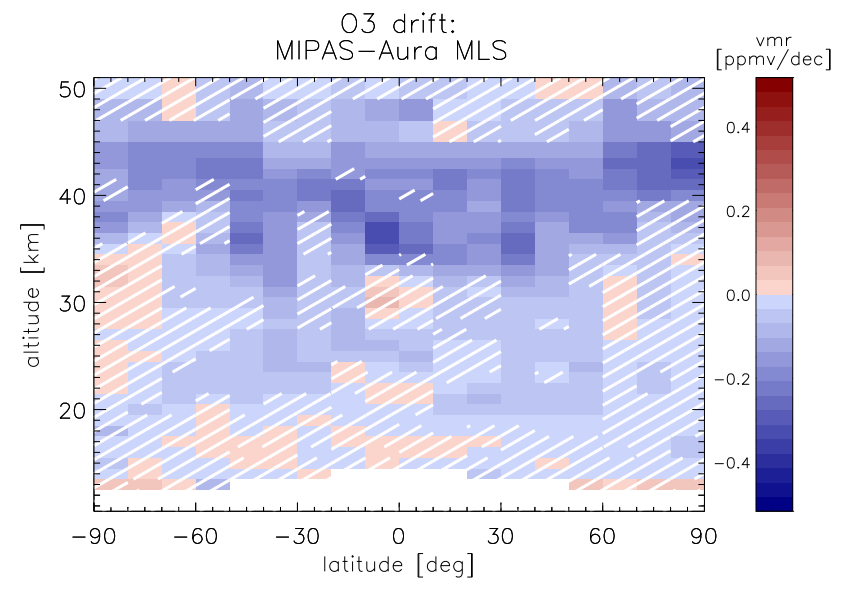

Fig. 4. Altitude-latitude cross-section of absolute drifts of MIPAS vs. Aura MLS ozone measurements. Hatched areas mean that the significance is less than 2 sigma.

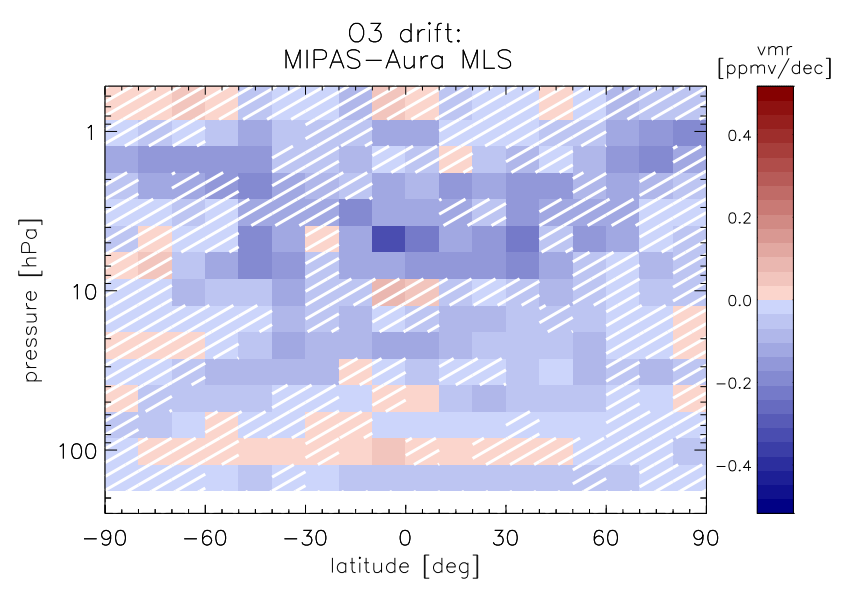

Fig. 5. Same as in Fig. 4 but represented on the Aura MLS pressure grid.

\section{Results}

\subsection{Drifts}

For the set of comparison instruments chosen, the resulting drifts cover a wide range of values. Comparisons with instruments which offer global or near-global coverage are displayed as altitude-latitude cross-sections of the linear term of the drift analysis. In these plots, hatched areas denote that the significance of the estimated drifts is less than 2 sigma. We have performed MIPAS drift estimations versus Aura MLS, ACE-FTS and Odin OSIRIS (Figs. 4-8). Estimates versus lidars are displayed in drift panels showing the linear term of the drift analysis as well as a 2-sigma uncertainty at each altitude grid point. In the following we will focus on discussing only drifts with 2-sigma significance or better. Blue colors in Figs. 4-8 indicate that the linear variation for the MIPAS data decreases more strongly than that of 


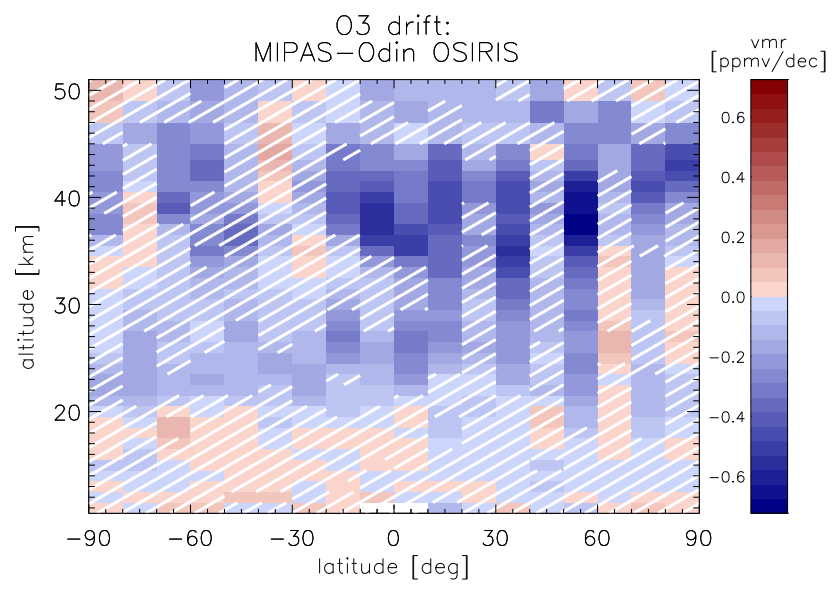

Fig. 6. Same as in Fig. 4 but for comparison versus Odin OSIRIS.

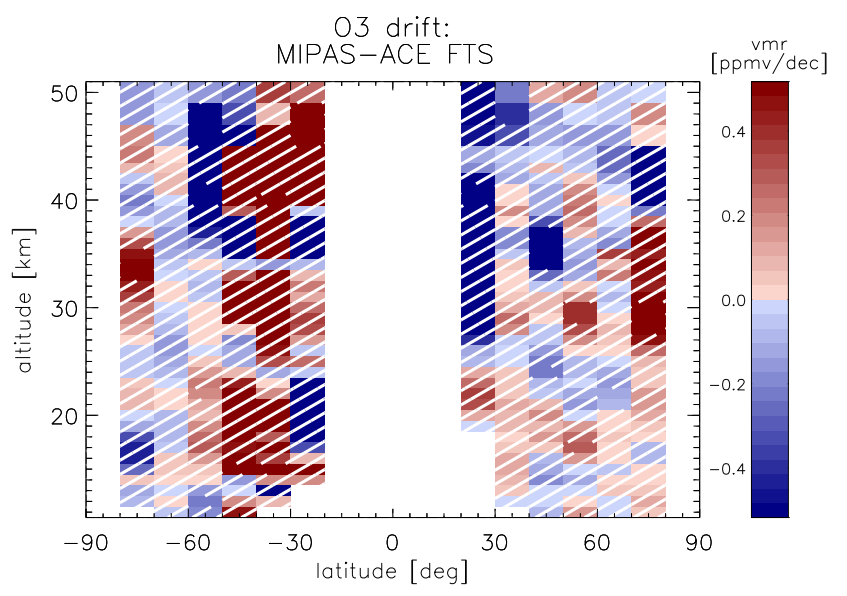

Fig. 7. Same as in Fig. 4 but for comparison versus ACE-FTS.

the reference instrument, while red colors denote a stronger increasing linear variation for the MIPAS data.

For the comparison versus Aura MLS the drift estimations on the altitude (Fig. 4) and on the pressure (Fig. 5) grid show very similar results. The distribution as well as the magnitude of the drifts are very alike. This means that the influence of a possible drift in ECMWF temperatures on the ozone drifts is quite small. The results exhibit only negative drifts, except from very few values at lower latitudes. The negative drifts range from near zero to approximately -0.33 ppmv decade ${ }^{-1}$ on the altitude grid and $-0.31 \mathrm{ppmv}^{-1 e c a d e^{-1}}$ on the pressure grid and seem to become slightly more negative with altitude up to $\sim 40 \mathrm{~km}(\sim 3 \mathrm{hPa})$. For Odin OSIRIS (Fig. 6) we find a similar pattern, but the absolute values range down to about $-0.55 \mathrm{ppmv}^{-}$decade $^{-1}$ at several grid points and even reach values around -0.7 ppmv decade ${ }^{-1}$ in a few cases. The plots of ACE-FTS (Figs. 7-8) look a bit different, mainly because we found very few significant drifts overall. This is presumably due to the fact that we find very few months (around

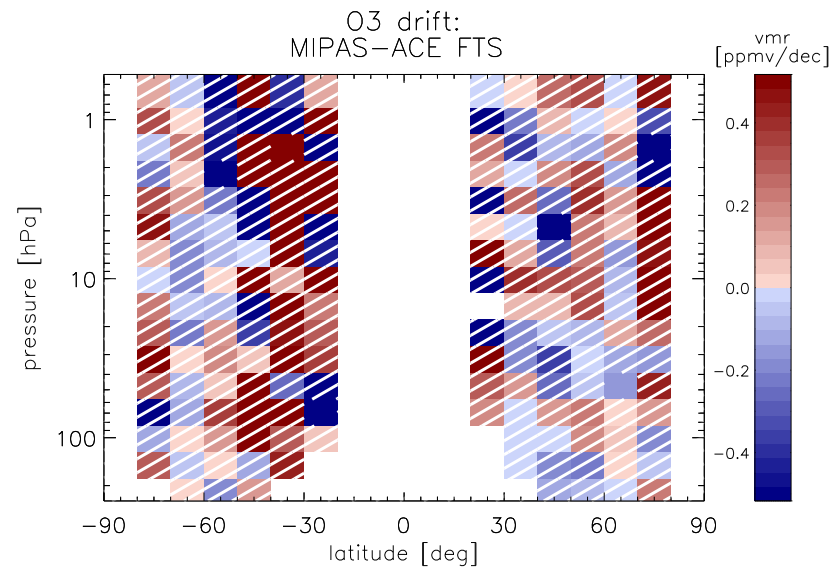

Fig. 8. Same as in Fig. 7 but represented on the Aura MLS pressure grid.

35 at the best) for which coincident measurements of MIPAS with ACE-FTS exist. Thus the trend estimation is based on far fewer monthly data points than for example the trend estimation versus the lidars (around 55 at the worst - e.g. for Lauder - up to more than 90 for other lidars), although their total number of measurements is a lot smaller than that of ACE-FTS. This might also explain the patchiness of the drifts estimated in the comparison with ACE-FTS. In the Northern Hemisphere the drifts are much smaller than for most of the Southern Hemisphere. Here the largest numbers of monthly data point occur, which allows a better fit. The large white area in the tropics, where no drifts could be calculated, results from ACE-FTS focusing on higher latitudes. Due to this, there are simply not enough months during which ACE-FTS measured at low latitudes, resulting in under-determination of the system of the multilinear parametric trend model. The remaining drifts do not seem to have a positive or negative majority in sign.

Aura MLS and Odin OSIRIS do not cover the same time period. In order to assess if including the first measurement period of MIPAS makes a difference, we also analysed the drifts of MIPAS versus Odin OSIRIS only for the lowresolution period of MIPAS (Fig. A2). It is obvious from these plots that differences compared to the drift analyses for the combined high and low spectral resolution time period of MIPAS are negligible.

Considering the lidars (Fig. 9) we assessed insignificant or negative drifts in most cases (Hohenpeissenberg, Table Mountain, Mauna Loa and Lauder). Only the comparison of MIPAS versus the lidar at Haute Provence shows positive drifts above $\sim 25 \mathrm{~km}$, which increase with altitude and even exceed 1.0 ppmv decade ${ }^{-1}$ around $40 \mathrm{~km}$. While the calculated drifts for the comparison of MIPAS with Mauna Loa and Lauder lidars are insignificant except for very few cases, we found significant negative drifts versus the lidar measurements at Hohenpeissenberg and Table Mountain above 

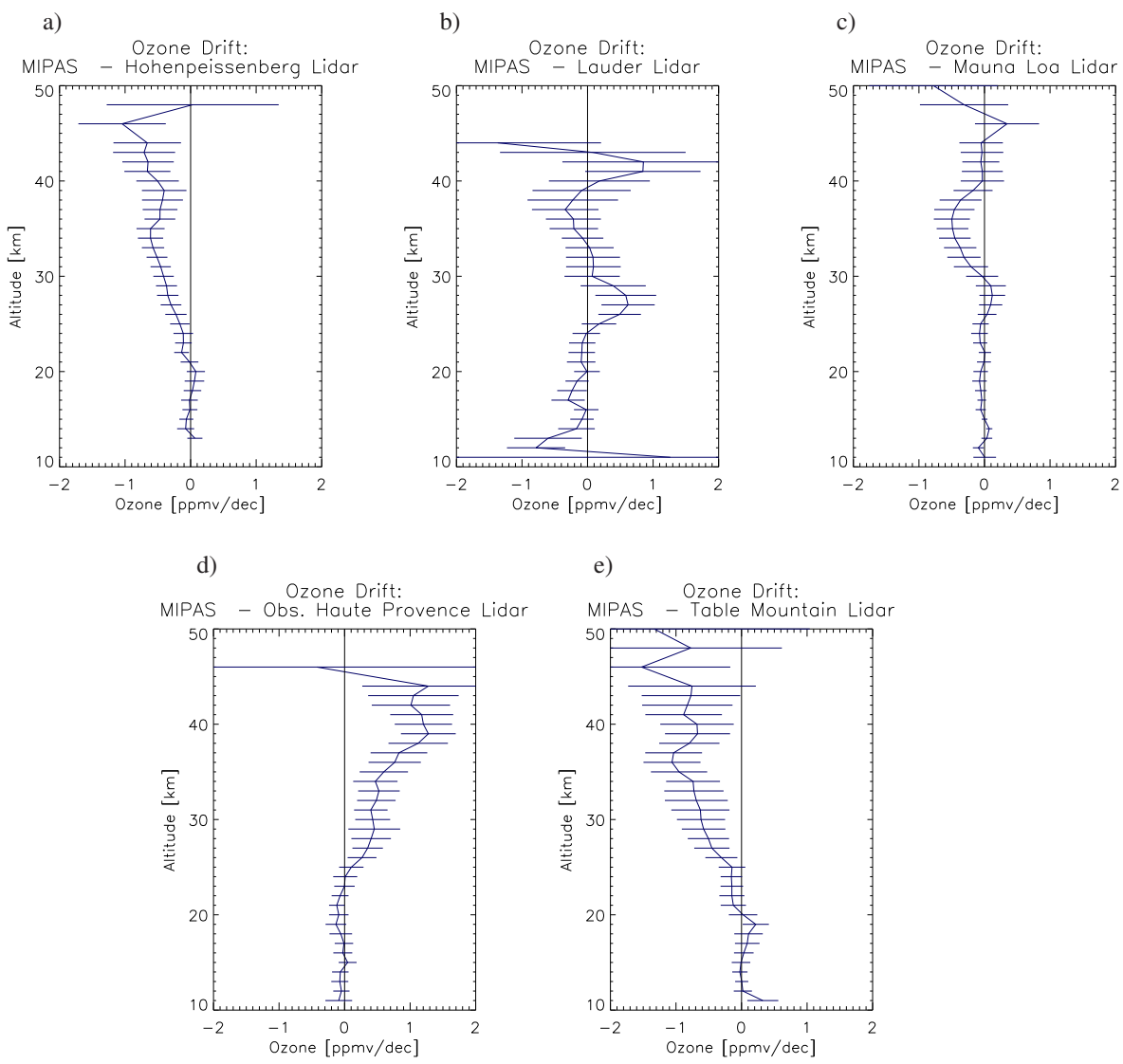

Fig. 9. Absolute drifts of MIPAS vs. (a) Hohenpeissenberg, (b) Lauder, (c) Mauna Loa, (d) Observatoire Haute Provence and (e) Table Mountain lidar ozone measurements. The error bars are the 2-sigma uncertainties of the estimated drifts.

$\sim 20 \mathrm{~km}$. As already observed for the analyses for MIPAS versus Aura MLS and Odin OSIRIS, these drifts seem to increase with altitude; but since the lidar data are not very reliable above $40 \mathrm{~km}$, it is difficult to verify maximum drift values at and above $40 \mathrm{~km}$, which are apparently present in the satellite-satellite comparisons. In order to facilitate comparison with recent research (Nair et al., 2012, p. 1310) we also calculated the relative drifts of MIPAS versus these lidars as described in Sect. 3.2 of this paper. The results are shown in Fig. A1. We find a striking resemblance with the findings of the aforementioned authors' comparison of Aura MLS with the lidars. They also find mainly insignificant drifts for comparisons of Aura MLS with the lidar measurements of Mauna Loa and Lauder. Drifts versus lidar measurements at Hohenpeissenberg and Table Mountain are predominantly negative above $\sim 20 \mathrm{~km}$ and increase with altitude, while positive drifts dominate the results found for comparisons with measurements at Haute Provence. Quantitatively our results are also in very good agreement with those which Nair et al. (2012) found for Aura MLS versus the lidars. Negative drifts below $40 \mathrm{~km}$ for MIPAS versus Hohenpeissenberg and Table Mountain measurements of down to $-8.2 \%$ decade $^{-1}$ and $-12.8 \%$ decade $^{-1}$ correspond to approximately $-1.0 \% \mathrm{yr}^{-1}$ and $-1.5 \% \mathrm{yr}^{-1}$ for Aura MLS from Nair et al. (2012), respectively. For lidar measurements at Haute Provence positive MIPAS drifts assessed in our study range up to $10 \%$ decade $^{-1}$ below $\sim 35 \mathrm{~km}$ and increase above, exceeding $15 \%$ decade $^{-1}$ close to $40 \mathrm{~km}$, while in the comparison of Aura MLS versus the same lidar measurements Nair et al. (2012) find values smaller than $1.0 \% \mathrm{yr}^{-1}$ up to about $39 \mathrm{~km}$ and values close to $1.5 \% \mathrm{yr}^{-1}$ above. This indicates that the drifts are probably (at least in part) related to the lidar instruments and not the satellite instruments, e.g. Aura MLS.

The most likely explanation for the drifts of MIPAS versus the other instruments is the ageing of the MIPAS detectors, which is not considered in the nonlinearity correction of the spectra used for the MIPAS ozone retrievals under investigation. The large number of coincident measurements available for the drift estimation between MIPAS and MLS implies that these drift estimates are the most significant ones, and in tendency these are confirmed by most of the other instruments under consideration. The good agreement between the drifts established from the comparison of MIPAS versus Aura MLS and the theoretically predicted drifts of MIPAS due to detector nonlinearity suggest that it is most likely that 


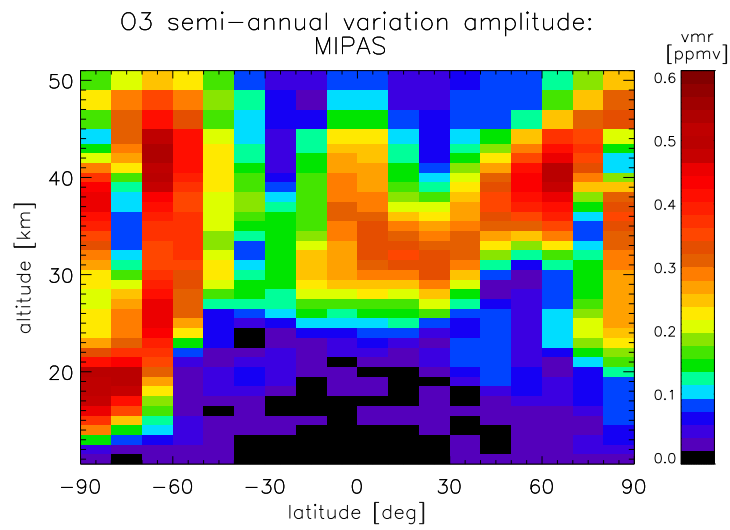

Fig. 10. Altitude-latitude cross-section of the amplitudes in ppmv of the semi-annual oscillation (6-month periodic variation) derived from the MIPAS time series.

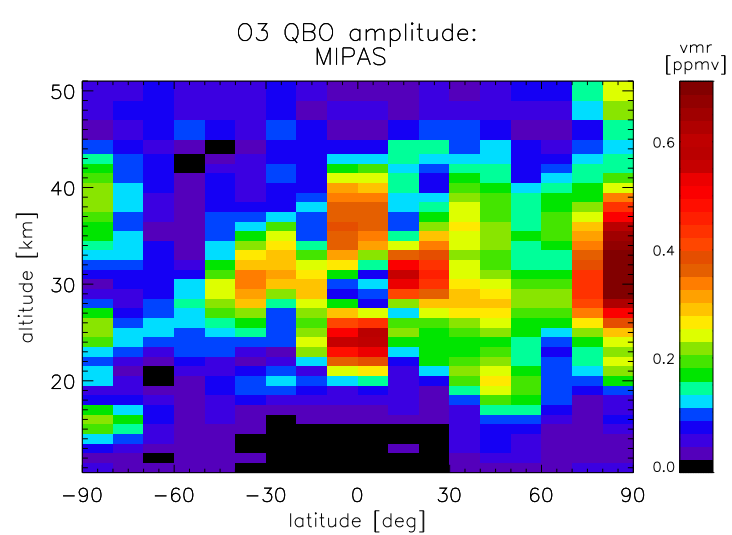

Fig. 11. Same as in Fig. 10 but for the quasi-biennial oscillation (QBO).

the drifts are for the most part originated in MIPAS, not Aura MLS. In addition there has been no indication of a possible drift in the Aura MLS ozone data so far (Hubert et al., 2012; Hubert et al., 2014). For these reasons, we believe that the assumption of an artificial drift of the order of 0 to -0.3 ppmv decade ${ }^{-1}$, depending on altitude, is well justified for MIPAS ozone.

\subsection{Amplitudes of the QBO, annual and semi-annual oscillation}

Among other quantities like the drifts and trends which were assessed in this work, we took a closer look at the altitudelatitude distribution of the amplitudes of the quasi-biennial (QBO) and semi-annual oscillation (SAO) as well as of the seasonal variation of the MIPAS ozone data. These quantities were also fitted during the trend estimation process.

The amplitude of the SAO (Fig. 10) shows approximately hemispherically symmetric distributions. We find an amplitude maximum of the ozone SAO signal which is centred

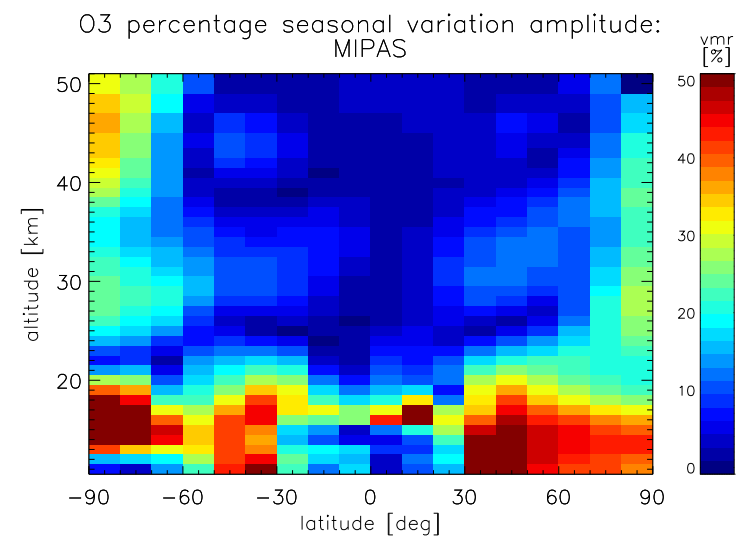

Fig. 12. Percentage amplitude of the seasonal variation of the MIPAS ozone time series (12-month periodic variation).

slightly above $30 \mathrm{~km}$ and exhibits maximum amplitudes of 0.5 ppmv. Beyond tropical latitudes the amplitude decreases rapidly to near-zero values, except for polar regions. These findings agree very well with the results of Huang et al. (2008), who analysed QBO and SAO ozone signals based on the Sounding of the Atmosphere using Broadband Emission Radiometry (SABER) satellite measurements for 2002 through 2005 from 20 to $100 \mathrm{~km}$ and for latitudes within $48^{\circ}$ north and south. They found good agreement with ozone data of the Microwave Limb Sounder on the Upper Atmosphere Research Satellite (UARS MLS) and assess an amplitude maximum of $\sim 0.5 \mathrm{ppmv}$ between 30 and $35 \mathrm{~km}$ for ozone. This is a result remarkably similar to ours.

The amplitude of the ozone $\mathrm{QBO}$ signal $A_{\mathrm{QBO}}$ is calculated as in Eq. (12) (cf. Eq. 1).

$A_{\mathrm{QBO}}=\frac{d_{1}}{\sin \left(\arctan \left(\frac{d_{1}}{c_{1}}\right)\right)}$

Its distribution, which is displayed in Fig. 11, shows a slightly more complex structure. Beside two tropical maxima around $25 \mathrm{~km}$, with slightly over $0.6 \mathrm{ppmv}$, and $35 \mathrm{~km}$, with approximately $0.4 \mathrm{ppmv}$, we find an additional subtropical maximum slightly above $30 \mathrm{~km}$ in each hemisphere. Of the latter two areas, the Northern Hemisphere one shows larger amplitudes with values of nearly $0.6 \mathrm{ppmv}$, while the Southern Hemisphere area is spatially larger but exhibits smaller maximum values of more than $0.3 \mathrm{ppmv}$ for several grid points but none reaching $0.4 \mathrm{ppmv}$.

The location of these maxima in the QBO ozone amplitude agrees very well with previous findings of e.g. Zawodny and McCormick (1991), who find tropical maxima in SAGE II data located between $20-27 \mathrm{~km}$ and $30-38 \mathrm{~km}$; Randel and $\mathrm{Wu}$ (1996), who report extra-tropical maxima located close to $30 \mathrm{~km}$ in latitude ranges of $10-60^{\circ}$ also from SAGE II data; as well as Fadnavis and Beig (2009), who find tropical maxima around $22 \mathrm{hPa}(\sim 26 \mathrm{~km})$ and $9 \mathrm{hPa}(\sim 32 \mathrm{~km})$ at equatorial latitudes and weaker extratropical maxima. The 
values of the reported maxima are larger though (about 1 ppmv (Randel et al., 1999), up to 1.4-1.6 ppmv (Fadnavis and Beig, 2009)), showing the larger values at the higher tropical maximum. MIPAS amplitudes are smaller, which might partly be due to the coarse vertical resolution especially around the upper maximum in tropical latitudes. The pattern could be understood as a periodic expansion and shrinking of the ozone maximum in the tropics with the QBO phase both in vertical and meridional direction. In this case, the amplitudes would be largest where the ozone gradient in both vertical and meridional direction is largest, which is what we observe (cf. Fig. 17, which is discussed in detail in Sect. 4.3).

We chose to show the seasonal variation in terms of relative values, because otherwise the important regions for this variation, along the tropopause, fade into the background since the absolute ozone values are much smaller in these regions than above. In the tropical tropopause layer (TTL) vertical motion has a great impact on the ozone amplitude, while at higher latitudes meridional mixing plays an important role. Around the tropical tropopause $\left(16-18 \mathrm{~km} ; \sim 20^{\circ} \mathrm{S}\right.$ to $\sim 20^{\circ} \mathrm{N}$ ) an area of strong seasonal variation is visible. Most values of the absolute amplitude in this region are within $\sim 0.01$ and $\sim 0.06 \mathrm{ppmv}$, with a few outliers reaching up to $\sim 0.11 \mathrm{ppmv}$. In the extratropical upper tropospherelower stratosphere (UTLS: $10-22 \mathrm{~km} ; 40-60^{\circ}$ south/north) the signal of the ozone variation is clearly visible around the tropopause and below. The values of the ozone amplitude in this region range from $\sim 0.1$ to $\sim 0.8 \mathrm{ppmv}$ in the Northern Hemisphere and from $\sim 0.01$ to $\sim 0.6 \mathrm{ppmv}$ in the Southern Hemisphere. We also see a signal in polar regions reaching up beyond $40 \mathrm{~km}$ with absolute values of up to 1.23 ppmv in the Northern Hemisphere. In the Southern Hemisphere around $30 \mathrm{~km}$ we find $\mathrm{AO}$ amplitudes of $\sim 1.0$ and $\sim 1.24 \mathrm{ppmv}$ between 40 and $50 \mathrm{~km}$. These results were found to be in very good agreement with recent findings. Eyring et al. (2010) report amplitudes of $\sim 0.05 \mathrm{ppmv}$ for NIWA (National Institute of Water and Atmospheric Research) observations between $20^{\circ} \mathrm{S}$ and $20^{\circ} \mathrm{N}$ at $100 \mathrm{hPa}$ $(\sim 16 \mathrm{~km})$, while some models show amplitudes ranging up to $\sim 0.1$ ppmv. For the extratropical UTLS region in the Northern Hemisphere, ozone AO amplitudes of $\sim 0.5 \mathrm{ppmv}$ were deduced from Aura MLS and a multimodel mean at $100 \mathrm{hPa}$, while at $200 \mathrm{hPa}(\sim 12 \mathrm{~km}) \sim 0.3 \mathrm{ppmv}$ were found for the ozone AO amplitude in Aura MLS and a slightly smaller amplitude of $\sim 0.2$ ppmv was assessed from the multimodel mean. For the Southern Hemisphere amplitudes of $\sim 0.4$ and $\sim 0.1 \mathrm{ppmv}$ were found at pressure levels of 100 and $200 \mathrm{hPa}$, respectively. These amplitudes are very similar to those we found in the MIPAS ozone data. Tegtmeier et al. (2013) report ozone AO amplitudes of $\sim 0.15 \mathrm{ppmv}$ for a multi-instrument mean at $80 \mathrm{hPa}(\sim 17 \mathrm{~km})$ between $20^{\circ}$ north and south for the period of 2005 to 2010 . For southern mid-latitudinal regions $\left(40-50^{\circ} \mathrm{S}\right)$ an amplitude of $\sim 0.15$ ppmv was deduced from the multi-instrument mean at

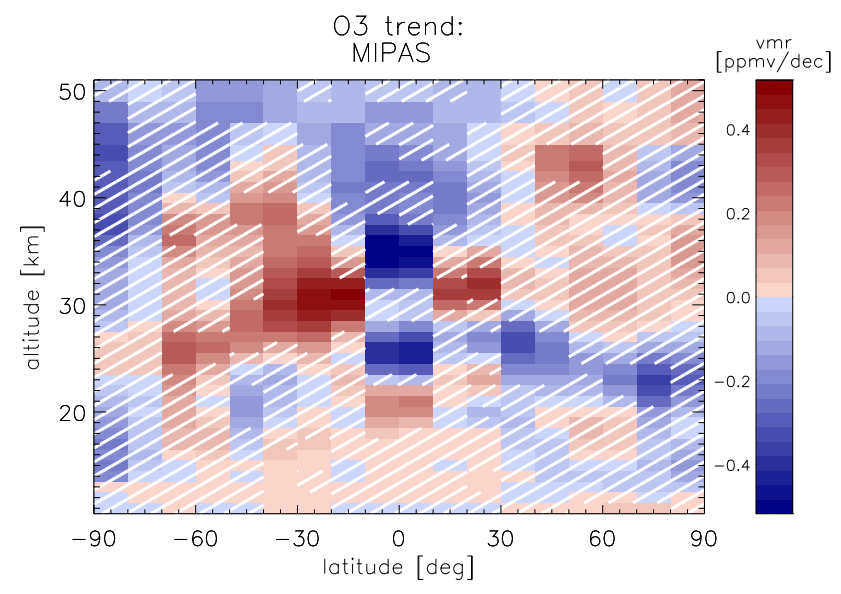

Fig. 13. Altitude-latitude cross-section of the linear variation of the MIPAS time series. As for the drifts, hatched areas indicate trends with less than 2-sigma significance level.

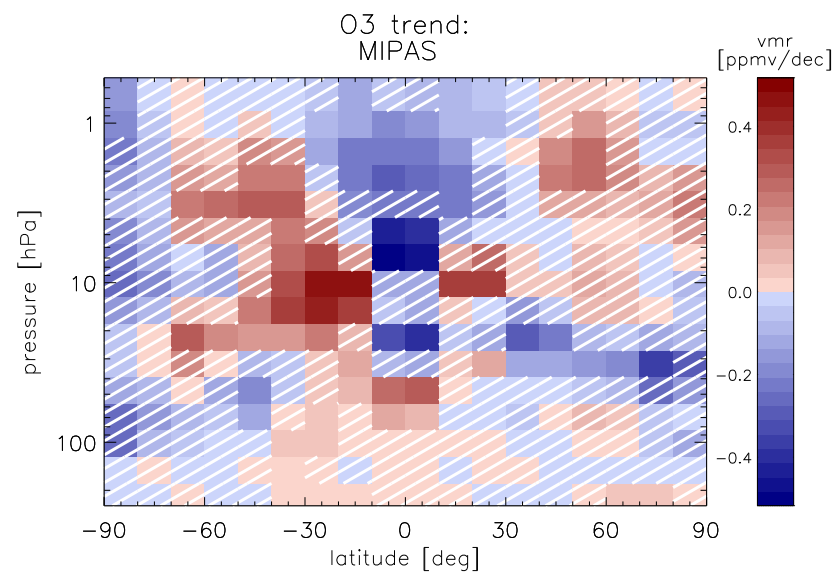

Fig. 14. Same as in Fig. 13 but represented on the Aura MLS pressure grid.

$200 \mathrm{hPa}$ for the same time period as mentioned above. In the Northern Hemisphere at $50 \mathrm{hPa}$ the multi-instrument mean shows an amplitude of $\sim 1.2 \mathrm{ppmv}$. Some of these amplitudes are larger than those deduced from MIPAS ozone data during this analyses. However, Tegtmeier et al. (2013) offer the explanation that this might be due to significantly better vertical resolution of some of the instruments used in their analysis.

\subsection{Linear variations (short-term trends)}

The linear term of the analysis of the MIPAS data estimated with the method described in Sect. 3.1 represents a shortterm trend of the evolution of stratospheric ozone during the past $10 \mathrm{yr}$. Similar to the drifts, we will concentrate on 2-sigma significant trends throughout the following discussion. As can be seen in Fig. 13, this excludes most of the results beyond $60^{\circ}$ north and south, where natural variability is large and thus the simple multilinear parametric trend 


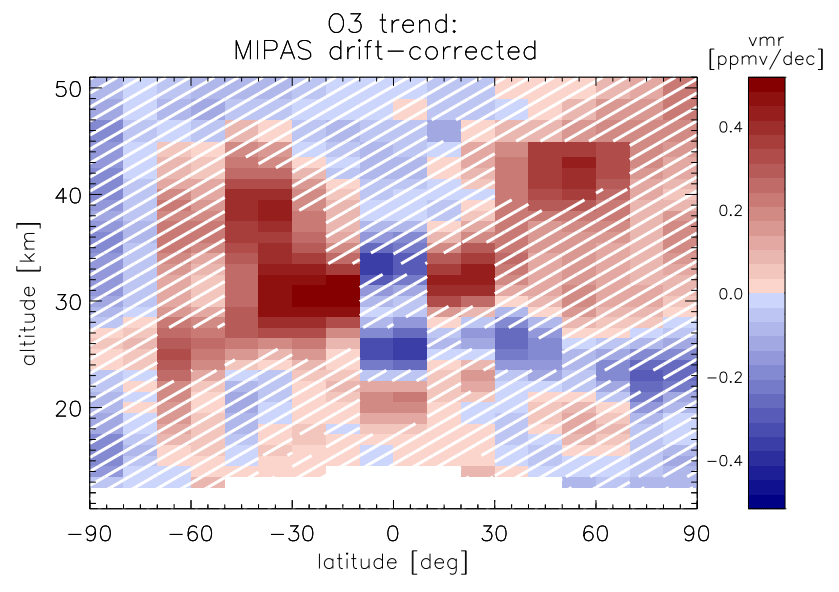

Fig. 15. Same as in Fig. 13 but corrected by the drifts estimated in comparison with Aura MLS. Two-sigma significances are based on the combined error of the trend and the drift.

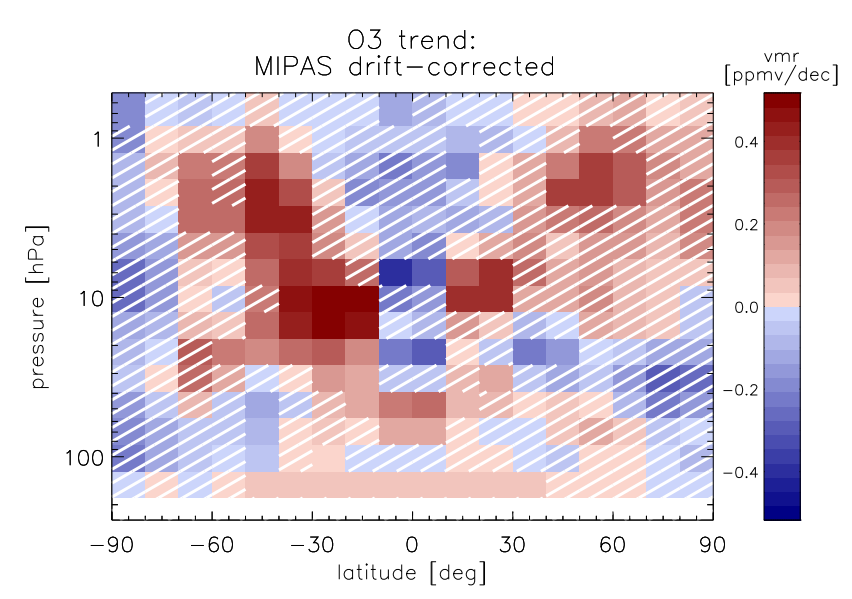

Fig. 16. Same as in Fig. 15 but displayed on the Aura MLS pressure grid.

model can presumably not fit the data properly. However, we should keep in mind that the non-random pattern of the estimated trends is a strong hint that increased significance could be achieved by a reduced spatial resolution of the analysis, both in the vertical and the latitudinal domain. Most of the trends below $20 \mathrm{~km}$ are non-significant, probably because ozone values are very small and MIPAS measurements are inhibited by clouds especially at low latitudes.

The results of this part of the trend analysis are displayed in Figs. 13 and 14 by means of an altitude-latitude/pressurelatitude cross-section, respectively. As already observed for the drift estimation versus Aura MLS, the features of both vertical grids look very similar. Both show a northernsouthern hemispherically asymmetric pattern, and we found a larger number of 2-sigma-significant trends for Southern Hemisphere latitudes in general. In addition these significant trends exhibit predominantly positive values. A pronounced positive area ranges from the subtropics to near-polar lati-

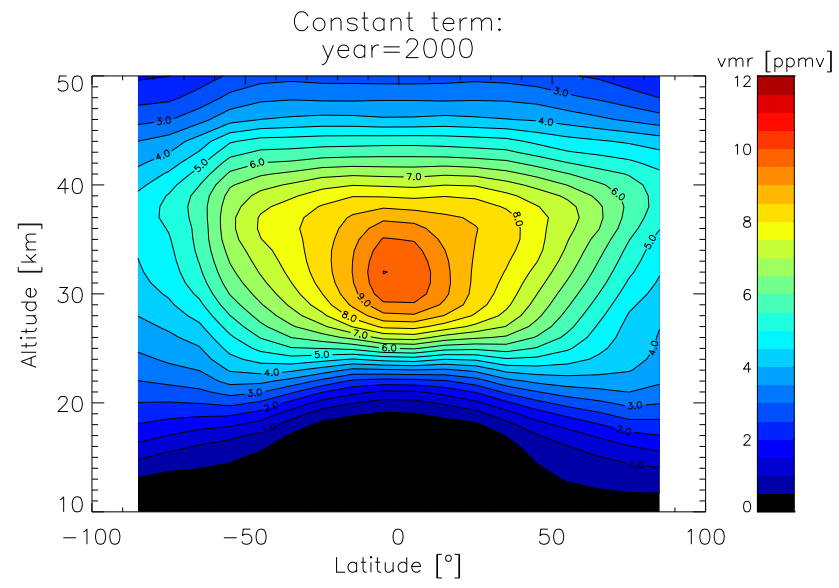

Fig. 17. Values of the MIPAS ozone regression function for the year 2000 .

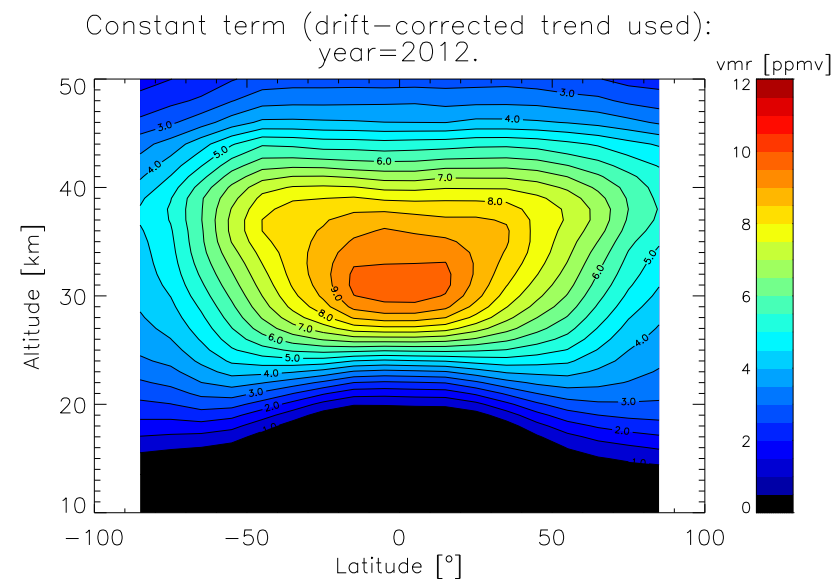

Fig. 18. Same as in Fig. 17 but for the year 2012. The drift-corrected MIPAS trends were used.

tudes centred approximately around $30 \mathrm{~km}(\sim 10 \mathrm{hPa})$ and with maximum ozone trend values of $+0.48 \mathrm{ppmv}$ decade $^{-1}$ $\left(+0.48\right.$ ppmv decade $\left.^{-1}\right)$. Apart from that we find a few smaller areas which also exhibit weaker positive trends, e.g. in the tropics around $20 \mathrm{~km}(\sim 55 \mathrm{hPa})$, at northern subtropical latitudes slightly above $30 \mathrm{~km}(\sim 10 \mathrm{hPa})$, at northern mid-latitudes at approximately $45 \mathrm{~km}(\sim 1.5 \mathrm{hPa})$ and at subtropical latitudes below $20 \mathrm{~km}(\sim 55 \mathrm{hPa})$ in both hemispheres. Negative trends are observed in the tropics in the form of a double-peak structure with maxima at approximately 25 and $35 \mathrm{~km}(\sim 25$ and $5 \mathrm{hPa})$ which reveal minimum trends of -0.56 ppmv decade ${ }^{-1}\left(-52\right.$ ppmv decade $\left.^{-1}\right)$. Considerably smaller values appear at Northern Hemisphere mid-latitudes between 20 and $30 \mathrm{~km}(\sim 55$ and $10 \mathrm{hPa})$.

Negative ozone trends in the tropical middle stratosphere have also been found in SCIAMACHY data (Gebhardt et al., 2014). Generally the trends shown in their paper agree with ours, but not in every detail. In particular the trends provided 


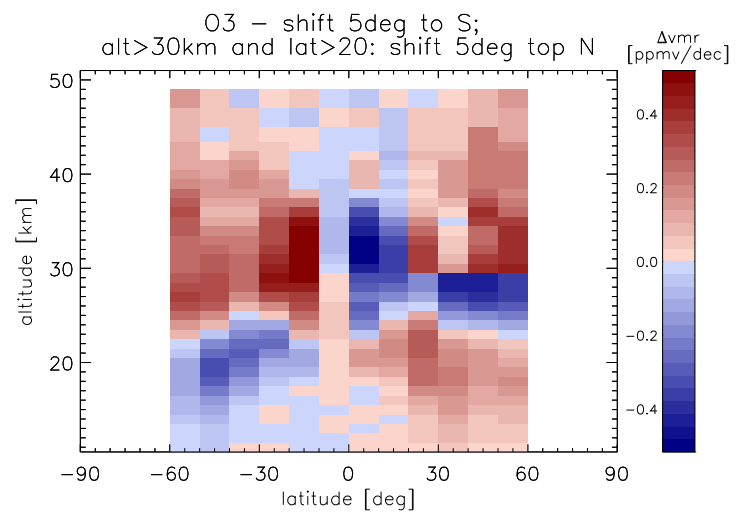

Fig. 19. Altitude-latitude cross-section showing the resulting trends when shifting the tropical mixing barriers below $30 \mathrm{~km}$ by 5 degrees to the south and expanding them by 5 degrees above that altitude.

by Gebhardt et al. (2014) for the middle tropics are more negative with only one negative peak.

Kyrölä et al. (2013) see less negative trends in the tropics around 30 to $35 \mathrm{~km}$ than Gebhardt et al. (2014). The trends by Kyrölä et al. (2013) are of the order of -2 to $-3 \%$ decade $^{-1}$. This is even a bit smaller than what we find, but in their paper the time period looked at (1997-2011) is a bit longer than ours and covers a slightly different time span in generel. Thus differences can be expected when comparing their results with ours. In the extratropics up to $\sim 50^{\circ} \mathrm{N} / \mathrm{S}$ Kyrölä et al. (2013) find predominantly positive or near-zero trends between 25 and $50 \mathrm{~km}$. Their trends are of the order of up to $+2 \%$ decade $^{-1}$ in these regions. This agrees considerably well with our results. Comparing our results with others of the post-mid-1990s period we find that the assessed changes are predominantly positive or near zero, except for the lower stratospheric tropics. While column ozone from ground-based and satellite measurements seem to exhibit non-changing ozone values in the mid-latitudes for both hemispheres after 1998 after showing an increase of $2 \%$ from 1996 to 1998, an increase in mid-latitudinal ozone was found for the Northern Hemisphere for the time period of 1996 to 2009 at altitude ranges of $12-15,20-25$ and 35$45 \mathrm{~km}$ with largest increases $(6 \%)$ at the lowest level and smaller values above. Southern Hemisphere mid-latitudinal trends were only found to be statistically significant at the highest level (35-45 km), exhibiting an increase of 1-3\% for the time period of 1996 to 2009 (cf. WMO (2011, Chapter 2, Table S2-1)). Tropical ozone trends from simulations show negative values right above the tropopause $(18-19 \mathrm{~km})$, presumably due to increased upwelling.

In addition to the trends estimated from MIPAS measurements, we also calculated "drift-corrected trends", again both on an altitude (Fig. 15) as well as on a pressure grid (Fig. 16). The displayed trends and associated errors were calculated as described in Sect. 3.4. We chose the drift estimates versus Aura MLS for correction of the MIPAS trends for two reasons. First, a drift of the order of magnitude such as the one established by comparison with Aura MLS can mostly be explained by drifts associated with the nonlinearity correction for the MIPAS detector as already mentioned in Sect. 4.1. Second, there has been no indication of a possible drift in Aura MLS ozone data so far. In addition to that the number of coinciding profiles with Aura MLS is the largest compared to all other instruments, even when using strict coincidence criteria, which presumably provides the most reliable analysis. Thus the drift estimate versus Aura MLS seems to be the most suitable candidate for shifting the MIPAS trends towards reality. While one might think that the drift-corrected MIPAS trends using Aura MLS for drift determination actually gives an Aura MLS ozone trend, this is not true: the MIPAS trend is inferred from a much larger data set than that used for drift estimation. For the drift estimation of MIPAS-Aura MLS coincidences had to be used, while the trends have been inferred from the entire MIPAS data set. Most of the negative ozone trends which were significant in the pure MIPAS estimates are no longer significant at 2-sigma level in the corrected version, especially at higher altitudes. In addition, significant areas with positive trends become larger and more significant. These results agree better with recent findings (e.g. WMO, 2011; Steinbrecht et al., 2009a) than the MIPAS trends without any correction. The few negative trends left are the tropical double-peak structure and Northern Hemisphere areas around 20 to $25 \mathrm{~km}(\sim 20 \mathrm{hPa})$. The latter feature is more pronounced in the altitude-latitude cross-section. A clear hemispherically asymmetric distribution is still visible in both figures. Positive values reach up to $+0.55 \mathrm{ppmv}^{-1 e c a d e^{-1}}$ $\left(+0.53\right.$ ppmv decade $\left.^{-1}\right)$ in the Southern Hemisphere and $+0.44 \mathrm{ppmv}_{\text {decade }}{ }^{-1}\left(+0.41 \mathrm{ppmv}^{\mathrm{decade}}{ }^{-1}\right)$ in the Northern Hemisphere, with the northern hemispheric areas slightly above $40 \mathrm{~km}(\sim 3 \mathrm{hPa})$ now reaching values of maximum $\quad+0.42 \mathrm{ppmv}_{\text {decade }}{ }^{-1} \quad\left(+0.37 \mathrm{ppmv}_{\text {decade }}{ }^{-1}\right)$. The tropical negative peaks show minimum values of $\quad-0.37 \mathrm{ppmv} \mathrm{decade}^{-1}$ and $-0.41 \mathrm{ppmv}^{-1 e c a d e^{-1}}$ $\left(-0.28\right.$ ppmv decade $^{-1}$ and -0.38 ppmv decade $\left.^{-1}\right)$ for the lower and the upper one, respectively.

A reasonable explanation for negative trends near the Equator is increased tropical upwelling, as has been suggested before (WMO, 2011), but only for altitudes slightly above the tropopause. So upwelling does not provide a sufficient explanation for the negative values in the tropical middle stratosphere. It cannot explain the double-peak structure either. The altitude-latitude cross-section of the amplitude of the QBO shows that the negative peaks in the trends coincide closely with the maxima in QBO amplitude. While the pattern of the QBO amplitude hints towards a periodic expansion and shrinking of the ozone maximum in the tropics (see Sect. 4.2), the trend pattern hints towards a vertical shrinking and latitudinal expansion of the ozone maximum. This is also most pronounced where the gradient in the ozone distribution is largest. According to this it is reasonable for the 
maxima of the QBO amplitude and the extrema of the trends to occur in similar areas. Figures 17 and 18 show the zonal ozone distribution calculated from the results of the parametric trend fit for the years 2000 and 2012, respectively. While the value of the MIPAS regression function for the year 2000 is a direct output of the trend fit process, the value for the year 2012 was calculated by extrapolating the ozone volume mixing ratio from the year 2000 to the year 2012 using the drift-corrected trend which was assessed previously. One can see a vertical shrinking and latitudinal expansion of the ozone maximum in the tropics.

The hemispherically asymmetric trend patterns shown in Fig. 15 could be explained by a shift of the subtropical mixing barriers by $5^{\circ}$ to the south over the observation period, as first indicated by Stiller et al. (2012). A simple way to mimic this shift is shown in Fig. 19: the zonal mean distribution of ozone as obtained from the constant terms of the parametric fits of the time series for all latitude-altitude bins has been shifted by $5^{\circ}$ to the south below altitudes of $30 \mathrm{~km}$. Above $30 \mathrm{~km}$, the Northern Hemisphere $\left(20^{\circ}\right.$ to $\left.60^{\circ} \mathrm{N}\right)$ has been shifted to the north, simulating a widening of the tropical pipe. The shifts have been applied between $60^{\circ} \mathrm{S}$ and $60^{\circ} \mathrm{N}$ only, since a shift of the polar mixing barriers was not expected. The differences between the original and the shifted distribution assumed to appear over a period of $10 \mathrm{yr}$ is shown in Fig. 19. The pattern of the change of the ozone distribution over a decade is stunningly similar to the linear trends observed in the real ozone distributions. Since the main features of the zonal ozone distribution are, to a large extent, ruled by the subtropical mixing barriers a shift of the barriers by $5^{\circ}$ to the south (and an expansion of the tropical pipe above $30 \mathrm{~km}$ ) would be able to explain the observed decadal linear trend to a large degree. We do not claim, however, that this is a climatological trend, but possibly rather a low-frequency natural variability, the causes of which are still unknown.

\section{Conclusions}

The investigations performed in this work offer an overall coherent picture. We calculated drifts of the MIPAS ozone time series versus several instruments which include satellite as well as ground-based experiments. Most of these analyses suggest that MIPAS ozone data most probably have a small negative drift, and thus trends calculated from the MIPAS data might exhibit values which are less positive (more negative) than in reality. Only a few comparisons suggest that MIPAS ozone data do not reveal a drift, such as the drift estimation versus ACE-FTS, or even hint at positive drifts like the analysis comparing MIPAS with the lidar at Observatoire Haute Provence. Magnitudes of the established negative drifts differ from minimum values of about $-0.3 \mathrm{ppmv}$ decade $^{-1}$ for Aura MLS to approximately -0.7 ppmv decade ${ }^{-1}$ for Odin OSIRIS and for some lidars at high altitudes. Due to recent studies on MIPAS' nonlinearity correction and the analysis versus Aura MLS, which presumably offers the most reliable drift estimates, we assume that a drift in MIPAS ozone data is most likely of a magnitude of 0 to -0.3 ppmv decade ${ }^{-1}$, depending on latitude, and thus we correct our trends estimated from MIPAS data by the drift estimates of the comparison with Aura MLS. The corrected trends agree well with recent findings and offer better agreement with those findings than the non-corrected trends. They range from approximately $-0.41 \mathrm{ppmv} \mathrm{decade}^{-1}$ in the tropics up to $+0.55 \mathrm{ppmv}^{-1 e c a d e^{-1}}$ at southern mid-latitudes $\left(-0.38\right.$ ppmv decade ${ }^{-1}$ to +0.53 ppmv decade ${ }^{-1}$ on the pressure grid). Significant areas exhibiting positive values increase spatially when correcting with the drifts estimated in comparison with Aura MLS, leaving mostly positive values. This is in very good agreement with results shown in WMO (2011). In the aforementioned work there are predominantly positive or close-to-zero trends found for the period after 1996/1997.

We observe a negative double-peak structure around the Equator, with minima at approximately 25 and $35 \mathrm{~km}$, exhibiting extreme values of $-0.37 \mathrm{ppmv}^{-1 e c a d e^{-1}}$

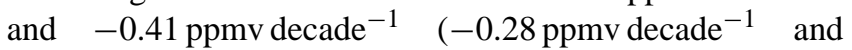
-0.38 ppmv decade ${ }^{-1}$ on the pressure grid), respectively, which coincide in altitude with the maxima of the amplitude of the ozone QBO. This coincidence of the tropical QBO maxima with the negative ozone trends occurs due to the ozone gradient being largest at these altitudes, so that the periodic vertical expansion and shrinking (in the case of the QBO) and the vertical flattening of the ozone maximum over the measured period (in the case of the trends) both are very obvious here. We find a clear hemispherically asymmetric pattern in the trends with the negative signs in the northern lower stratosphere and positive values in the southern lower stratosphere $(20-30 \mathrm{~km})$. This, together with negative trends at tropical mid-stratospheric altitudes can be mimicked by shifting the zonal ozone distribution $30 \mathrm{~km}$ by $5^{\circ}$ to the south and expanding the tropical pipe by $5^{\circ}$ to the north and south above, simulating mainly a respective shift of the subtropical mixing barriers over the observation period. Even the positive trends just above the tropical tropopause can be simulated by the shift of the subtropical mixing barriers to the south. Such a shift is not necessarily a climatological trend, but possibly rather a low-frequency natural variation, the cause of which is still unknown.

The altitude-latitude cross-sections of the amplitudes of the QBO, SAO and the seasonal variation agree well with previous results. In the case of the SAO, both the altitudelatitude distribution as well as the magnitude are very similar to previous findings, while the estimated values of the ozone QBO amplitude are smaller than those found in other studies. Our results for the amplitudes of the seasonal variation show reasonable altitude-latitude distributions and reveal similar magnitudes to previous findings. 


\section{Appendix A}

\section{Drifts}
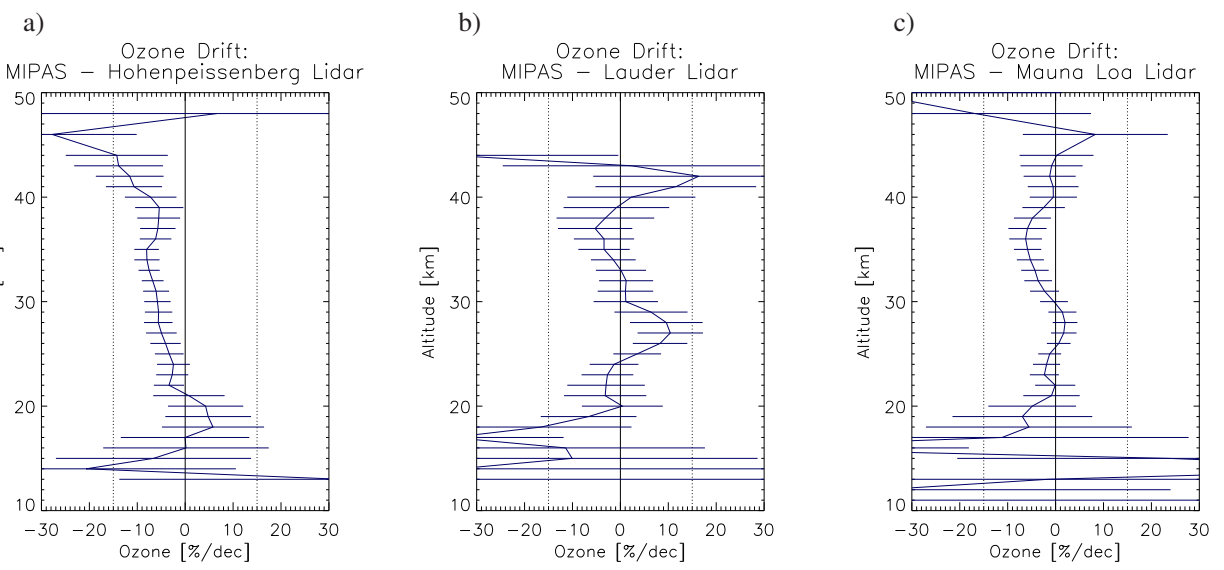

d)

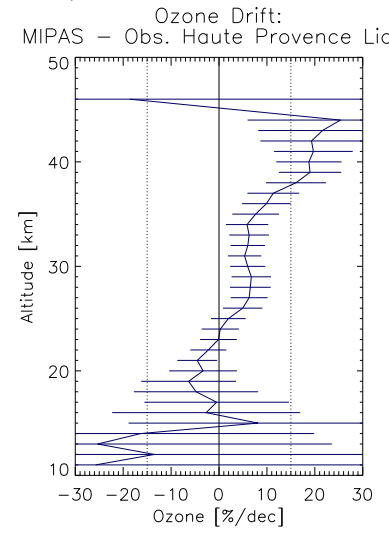

e)

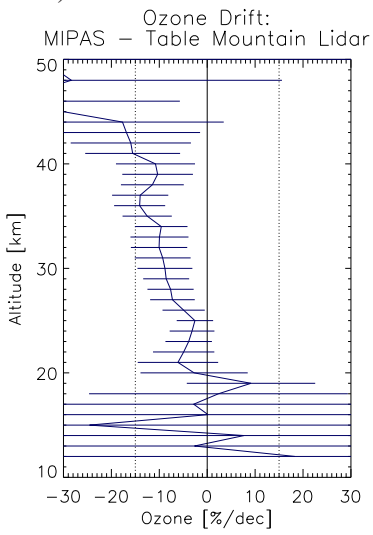

Fig. A1. Same as Fig. 9 but showing relative drifts.

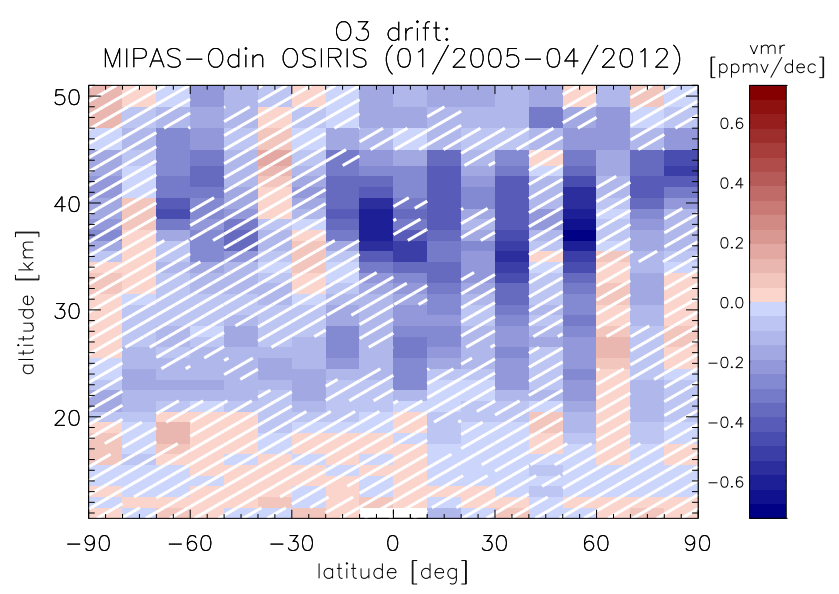

Fig. A2. Altitude-latitude cross-section of absolute drifts of MIPAS vs. Odin OSIRIS ozone measurements only for the time period from January 2005 to April 2012. Hatching as described before. a)

Ozone Drift (01/2005-04/2012): MIPAS - Hohenpeissenberg Lidar

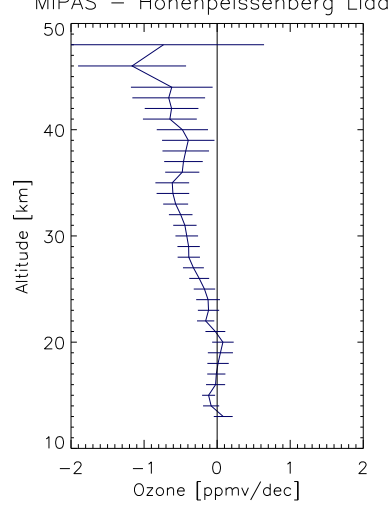

b)

Ozone Drift (01/2005-03/2012):

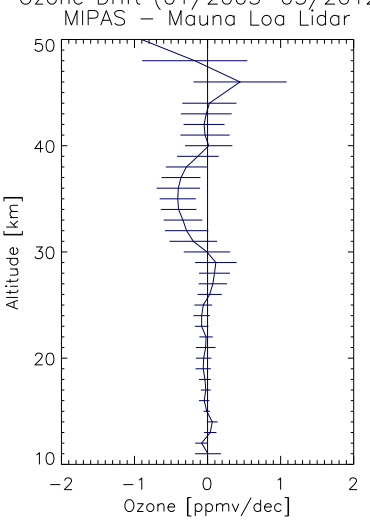

Fig. A3. Same as Fig. 9a and c but only for the time period of 2005 to 2012 . 
Acknowledgements. The retrievals of IMK/IAA were partly performed on the HP XC4000 of the Scientific Supercomputing Center (SSC) Karlsruhe under project grant MIPAS. IMK data analysis was supported by DLR under contract number 50EE0901. MIPAS level-1b data were provided by ESA. We acknowledge support by Deutsche Forschungsgemeinschaft and Open Access Publishing Fund of Karlsruhe Institute of Technology. The Atmospheric Chemistry Experiment (ACE), also known as SCISAT, is a Canadian-led mission mainly supported by the Canadian Space Agency and the Natural Sciences and Engineering Research Council of Canada. Work at the Jet Propulsion Laboratory, California Institute of Technology, was carried out under contract with the National Aeronautics and Space Administration.

The service charges for this open access publication

have been covered by a Research Centre of the

Helmholtz Association.

Edited by: R. Eckman

\section{References}

Brinksma, E. J., Bergwerff, J. B., Bodeker, G. E., Boersma, K. F., Boyd, I. S., Connor, B. J., de Haan, J. F., Hogervorst, W., Hovenier, J. W., Parrish, A., Tsou, J. J., Zawodny, J. M., and Swart, D. P. J.: Validation of 3 years of ozone measurements over Network for the Detection of Stratospheric Change station Lauder, New Zealand, J. Geophys. Res., 105, 17291, doi:10.1029/2000JD900143, 2000.

Degenstein, D. A., Bourassa, A. E., Roth, C. Z., and Llewellyn, E. J.: Limb scatter ozone retrieval from 10 to $60 \mathrm{~km}$ using a multiplicative algebraic reconstruction technique, Atmos. Chem. Phys., 9, 6521-6529, doi:10.5194/acp-9-6521-2009, 2009.

Dobson, G. M. B.: Ozone in the Upper Atmosphere and its Relation to Meteorology, Nature, 127, 668-672, doi:10.1038/127668a0, 1931.

Dobson, G. M. B.: Forty years research on atmospheric ozone at Oxford: a history, Appl. Optics, 7, 387, doi:10.1364/AO.7.000387, 1968.

Dupuy, E., Walker, K. A., Kar, J., Boone, C. D., McElroy, C. T., Bernath, P. F., Drummond, J. R., Skelton, R., McLeod, S. D., Hughes, R. C., Nowlan, C. R., Dufour, D. G., Zou, J., Nichitiu, F., Strong, K., Baron, P., Bevilacqua, R. M., Blumenstock, T., Bodeker, G. E., Borsdorff, T., Bourassa, A. E., Bovensmann, H., Boyd, I. S., Bracher, A., Brogniez, C., Burrows, J. P., Catoire, V., Ceccherini, S., Chabrillat, S., Christensen, T., Coffey, M. T., Cortesi, U., Davies, J., De Clercq, C., Degenstein, D. A., De Mazière, M., Demoulin, P., Dodion, J., Firanski, B., Fischer, H., Forbes, G., Froidevaux, L., Fussen, D., Gerard, P., GodinBeekmann, S., Goutail, F., Granville, J., Griffith, D., Haley, C. S., Hannigan, J. W., Höpfner, M., Jin, J. J., Jones, A., Jones, N. B., Jucks, K., Kagawa, A., Kasai, Y., Kerzenmacher, T. E., Kleinböhl, A., Klekociuk, A. R., Kramer, I., Küllmann, H., Kuttippurath, J., Kyrölä, E., Lambert, J.-C., Livesey, N. J., Llewellyn, E. J., Lloyd, N. D., Mahieu, E., Manney, G. L., Marshall, B. T., McConnell, J. C., McCormick, M. P., McDermid, I. S., McHugh, M., McLinden, C. A., Mellqvist, J., Mizutani, K., Murayama, Y., Murtagh, D. P., Oelhaf, H., Parrish, A., Petelina, S. V., Piccolo, C., Pommereau, J.-P., Randall, C. E., Robert, C., Roth, C.,
Schneider, M., Senten, C., Steck, T., Strandberg, A., Strawbridge, K. B., Sussmann, R., Swart, D. P. J., Tarasick, D. W., Taylor, J. R., Tétard, C., Thomason, L. W., Thompson, A. M., Tully, M. B., Urban, J., Vanhellemont, F., Vigouroux, C., von Clarmann, T., von der Gathen, P., von Savigny, C., Waters, J. W., Witte, J. C., Wolff, M., and Zawodny, J. M.: Validation of ozone measurements from the Atmospheric Chemistry Experiment (ACE), Atmos. Chem. Phys., 9, 287-343, doi:10.5194/acp-9-287-2009, 2009.

Eyring, V., Shepherd, T. G., and Waugh, D. W. (Eds.): SPARC Report on the Evaluation of Chemistry-Climate Models, SPARC Report No.5, WCRP-132, WMO/TD-No. 1526, SPARC CCMVal, 2010.

Fadnavis, S. and Beig, G.: Quasi-biennial oscillation in ozone and temperature over tropics, J. Atmos. Sol.-Terr. Phys., 71, 257263, doi:10.1016/j.jastp.2008.11.012, 2009.

Farman, J. C., Gardiner, B. G., and Shanklin, J. D.: Large losses of total ozone in Antarctica reveal seasonal $\mathrm{ClO}_{\mathrm{x}} / \mathrm{NO}_{\mathrm{x}}$ interaction, Nature, 315, 207-210, doi:10.1038/315207a0, 1985.

Fischer, H., Birk, M., Blom, C., Carli, B., Carlotti, M., von Clarmann, T., Delbouille, L., Dudhia, A., Ehhalt, D., Endemann, M., Flaud, J. M., Gessner, R., Kleinert, A., Koopman, R., Langen, J., López-Puertas, M., Mosner, P., Nett, H., Oelhaf, H., Perron, G., Remedios, J., Ridolfi, M., Stiller, G., and Zander, R.: MIPAS: an instrument for atmospheric and climate research, Atmos. Chem. Phys., 8, 2151-2188, doi:10.5194/acp-8-2151-2008, 2008.

Froidevaux, L., Jiang, Y. B., Lambert, A., Livesey, N. J., Read, W. G., Waters, J. W., Browell, E. V., Hair, J. W., Avery, M. A., McGee, T. J., Twigg, L. W., Sumnicht, G. K., Jucks, K. W., Margitan, J. J., Sen, B., Stachnik, R. A., Toon, G. C., Bernath, P. F., Boone, C. D., Walker, K. A., Filipiak, M. J., Harwood, R. S., Fuller, R. A., Manney, G. L., Schwartz, M. J., Daffer, W. H., Drouin, B. J., Cofield, R. E., Cuddy, D. T., Jarnot, R. F., Knosp, B. W., Perun, V. S., Snyder, W. V., Stek, P. C., Thurstans, R. P., and Wagner, P. A.: Validation of Aura Microwave Limb Sounder stratospheric ozone measurements, J. Geophys. Res.Atmos., 113, D15S20, doi:10.1029/2007JD008771, 2008.

Gebhardt, C., Rozanov, A., Hommel, R., Weber, M., Bovensmann, H., Burrows, J. P., Degenstein, D., Froidevaux, L., and Thompson, A. M.: Stratospheric ozone trends and variability as seen by SCIAMACHY from 2002 to 2012, Atmos. Chem. Phys., 14, 831-846, doi:10.5194/acp-14-831-2014, 2014.

Götz, F. W. P., Meetham, A. R., and Dobson, G. M. B.: The Vertical Distribution of Ozone in the Atmosphere, Royal Society of London Proceedings Series A, 145, 416-446, doi:10.1098/rspa.1934.0109, 1934.

Huang, F. T., Mayr, H. G., Reber, C. A., Russell III, J. M., Mlynczak, M. G., and Mengel, J. G.: Ozone quasi-biennial oscillations (QBO), semiannual oscillations (SAO), and correlations with temperature in the mesosphere, lower thermosphere, and stratosphere, based on measurements from SABER on TIMED and MLS on UARS, J. Geophys. Res., 113, A01316, doi:10.1029/2007JA012634, 2008.

Hubert, D., Verhoelst, T., Keppens, A., Granville, J., and Lambert, J.-C.: Network-based evaluation of fourteen satellite limb/occultation profilers for the next SPARC and WMO ozone trend assessments, Talk at Quadrennial Ozone Symposium 2012, Toronto, 2012 
Hubert, D., Lambert, J.-C., Verhoelst, T., Granville, J., and Keppens, A.: Ground-based assessment of the bias and long-term stability of fourteen limb and occultation ozone profile data records, Atmos. Meas. Tech. Discuss., in preparation, 2014.

Kiefer, M., Aubertin, G., Birk, M., De Laurentis, M., Eckert, E., Kleinert, A., Perron, G., and Wagner, G.: Impact of Improved Corrections for MIPAS Detector Non-Linearity, in: Atmospheric Composition Validation and Evolution, Frascati, 13-15 March 2013, Abstract Book, p. 38, ESA, 2013.

Kirgis, G., Leblanc, T., McDermid, I. S., and Walsh, T. D.: Stratospheric ozone interannual variability (1995-2011) as observed by lidar and satellite at Mauna Loa Observatory, HI and Table Mountain Facility, CA, Atmos. Chem. Phys., 13, 5033-5047, doi:10.5194/acp-13-5033-2013, 2013.

Kyrölä, E., Laine, M., Sofieva, V., Tamminen, J., Päivärinta, S.-M., Tukiainen, S., Zawodny, J., and Thomason, L.: Combined SAGE II-GOMOS ozone profile data set for 1984-2011 and trend analysis of the vertical distribution of ozone, Atmos. Chem. Phys., 13, 10645-10658, doi:10.5194/acp-13-10645-2013, 2013.

Laeng, L., Grabowski, U., von Clarmann, T., Stiller, G., Kellmann, S., Kiefer, M., Linden, A., Lossow, S., Bathgate, T., Bernath, P., Boone, C. D., Clerbaux, C., Degenstein, D. and Fritz, S., Froidevaux, L., Hervig, M., Hoppel, K., Lumpe, J., McHugh, M., Sano, T., Sofieva, V., Suzuki, M., Tamminen, J., Urban, J., Walker, K., Weber, M., and Zawodny, J.: Validation of MIPAS IMK/IAA ozone profiles, poster at Quadrennial Ozone Symposium 2012, Toronto, 27-31 August, 2012.

Llewellyn, E., Lloyd, N. D., Degenstein, D. A., Gattinger, R. L., Petelina, S. V., Bourassa, A. E., Wiensz, J. T., Ivanov, E. V., McDade, I. C., Solheim, B. H., McConnell, J. C., Haley, C. S., von Savigny, C., Sioris, C. E., McLinden, C. A., Griffioen, E., Kaminski, J., Evans, W. F. J., Puckrin, E., Strong, K., Wehrle, V., Hum, R. H., Kendall, D. J. W., Matsushita, J., Murtagh, D. P., Brohede, S., Stegman, J., Witt, G., Barnes, G., Payne, W. F., Piche, L., Smith, K., Warshaw, G., Deslauniers, D. L., Marchand, P., Richardson, E. H., King, R. A., Wevers, I., McCreath, W., Kyrola, E., Oikarinen, L., Leppelmeier, G. W., Auvinen, H., Megie, G., Hauchecorne, A., Lefevre, F., de La Noe, J., Ricaud, P., Frisk, U., Sjoberg, F., von Scheele, F., and Nordh, L.: The OSIRIS instrument on the Odin spacecraft, Canadian Journal of Physics, 82, 411-422, doi:10.1139/p04-005, 2004.

McDermid, I. S., Walsh, T. D., Deslis, A., and White, M. L.: Optical systems design for a stratospheric lidar system, Appl. Optics, 34, 6201, doi:10.1364/AO.34.006201, 1995.

McDermid, S. I., Godin, S. M., and Lindqvist, L. O.: Ground-based laser DIAL system for long-term measurements of stratospheric ozone, Appl. Optics, 29, 3603-3612, doi:10.1364/AO.29.003603, 1990.

Megie, G., Allain, J. Y., Chanin, M. L., and Blamont, J. E.: Vertical profile of stratospheric ozone by lidar sounding from the ground, Nature, 270, 329-331, doi:10.1038/270329a0, 1977.

Molina, M. J. and Rowland, F. S.: Stratospheric sink for chlorofluoromethanes: Chlorine atom-catalysed destruction of ozone, Nature, 249, 810-812, 1974.

Nair, P. J., Godin-Beekmann, S., Froidevaux, L., Flynn, L. E., Zawodny, J. M., Russell III, J. M., Pazmiño, A., Ancellet, G., Steinbrecht, W., Claude, H., Leblanc, T., McDermid, S., van Gijsel, J. A. E., Johnson, B., Thomas, A., Hubert, D., Lambert, J.-C., Nakane, H., and Swart, D. P. J.: Relative drifts and sta- bility of satellite and ground-based stratospheric ozone profiles at NDACC lidar stations, Atmos. Meas. Tech., 5, 1301-1318, doi:10.5194/amt-5-1301-2012, 2012.

Randel, W. J. and Wu, F.: Isolation of the Ozone QBO in SAGE II Data by Singular-Value Decomposition, J. Atmos. Sci., 53, 2546-2560, doi:10.1175/15200469(1996)053<2546:IOTOQI>2.0.CO;2, 1996.

Randel, W. J., Wu, F., Swinbank, R., Nash, J., and O'Neill, A.: Global QBO Circulation Derived from UKMO Stratospheric Analyses, J. Atmos. Sci., 56, 457-474, doi:10.1175/15200469(1999)056<0457:GQCDFU>2.0.CO;2, 1999.

Rodgers, C. D.: Inverse Methods for Atmospheric Sounding: Theory and Practice, vol. 2 of Series on Atmospheric, Oceanic and Planetary Physics, F. W. Taylor, ed., World Scientific, 2000.

Schoeberl, M. R., Douglass, A. R., Hilsenrath, E., Bhartia, P. K., Beer, R., Waters, J. W., Gunson, M. R., Froidevaux, L., Gille, J. C., Barnett, J. J., Levelt, P. F., and de Cola, P.: Overview of the EOS Aura Mission, IEEE T. Geosci. Remote, 44, 1066-1074, doi:10.1109/TGRS.2005.861950, 2006.

Steinbrecht, W., Claude, H., Schonenborn, F., McDermid, I. S., Leblanc, T., Godin-Beekmann, S., Keckhut, P., Hauchecorne, A., van Gijsel, J. A. E., Swart, D. P. J., Bodeker, G. E., Parrish, A., Boyd, I. S., Kampfer, N., Hocke, K., Stolarski, R. S., Frith, S. M., Thomason, L. W., Remsberg, E. E., von Savigny, C., Rozanov, A., and Burrows, J. P.: Ozone and temperature trends in the upper stratosphere at five stations of the Network for the Detection of Atmospheric Composition Change, Int. J. Remote Sens., 30, 3875-3886, doi:10.1080/01431160902821841, 2009a.

Steinbrecht, W., McGee, T. J., Twigg, L. W., Claude, H., Schönenborn, F., Sumnicht, G. K., and Silbert, D.: Intercomparison of stratospheric ozone and temperature profiles during the October 2005 Hohenpeißenberg Ozone Profiling Experiment (HOPE), Atmos. Meas. Tech., 2, 125-145, doi:10.5194/amt-2-125-2009, 2009b.

Stiller, G., Von Clarmann, T., Eckert, E., Haenel, F., Funke, B., Glatthor, N., Grabowski, U., Kellmann, S., Kiefer, M., Linden, A., Lossow, S., and López-Puertas, M.: Global observation of stratospheric age of air, its temporal variation, and correlation with ozone, Poster at Quadrennial Ozone Symposium 2012, Toronto, 27-31 August, 2012.

Stiller, G. P., Kiefer, M., Eckert, E., von Clarmann, T., Kellmann, S., García-Comas, M., Funke, B., Leblanc, T., Fetzer, E., Froidevaux, L., Gomez, M., Hall, E., Hurst, D., Jordan, A., Kämpfer, N., Lambert, A., McDermid, I. S., McGee, T., Miloshevich, L., Nedoluha, G., Read, W., Schneider, M., Schwartz, M., Straub, C., Toon, G., Twigg, L. W., Walker, K., and Whiteman, D. N.: Validation of MIPAS IMK/IAA temperature, water vapor, and ozone profiles with MOHAVE-2009 campaign measurements, Atmos. Meas. Tech., 5, 289-320, doi:10.5194/amt-5-289-2012, 2012.

Stiller, G. P., von Clarmann, T., Haenel, F., Funke, B., Glatthor, N., Grabowski, U., Kellmann, S., Kiefer, M., Linden, A., Lossow, S., and López-Puertas, M.: Observed temporal evolution of global mean age of stratospheric air for the 2002 to 2010 period, Atmos. Chem. Phys., 12, 3311-3331, doi:10.5194/acp-12-33112012, 2012.

Tegtmeier, S., Hegglin, M. I., Anderson, J., Bourassa, A. andBrohede, S., Degenstein, D., Froidevaux, L., Fuller, L., Funke, B., Gille, J., Jones, A., Kasai, Y., Kyrola, E., Lingenfelser, G., Lumpe, J., Nardi, B., Neu, J., Pendlebury, D., Remsberg, E., 
Rozanov, A., Smith, L., Toohey, M., Urban, J., von Clarmann, T., Walker, K., and Wang, R.: The SPARC Data Initiative: A comparison of ozone climatologies from international limb satellite sounders, J. Geophys. Res., 118, 12229-12247, 2013.

von Clarmann, T., Höpfner, M., Kellmann, S., Linden, A., Chauhan, S., Funke, B., Grabowski, U., Glatthor, N., Kiefer, M., Schieferdecker, T., Stiller, G. P., and Versick, S.: Retrieval of temperature, $\mathrm{H}_{2} \mathrm{O}, \mathrm{O}_{3}, \mathrm{HNO}_{3}, \mathrm{CH}_{4}, \mathrm{~N}_{2} \mathrm{O}, \mathrm{ClONO}_{2}$ and $\mathrm{ClO}$ from MIPAS reduced resolution nominal mode limb emission measurements, Atmos. Meas. Tech., 2, 159-175, doi:10.5194/amt-2-159-2009, 2009.

von Clarmann, T., Stiller, G., Grabowski, U., Eckert, E., and Orphal, J.: Technical Note: Trend estimation from irregularly sampled, correlated data, Atmos. Chem. Phys., 10, 6737-6747, doi:10.5194/acp-10-6737-2010, 2010.
Waters, J. W., Froidevaux, L., Harwood, R. S., Jarnot, R. F., Pickett, H. M., Read, W. G., Siegel, P. H., Cofield, R. E., Filipiak, M. J., Flower, D. A., Holden, J. R., Lau, G. K., Livesey, N. J., Manney, G. L., Pumphrey, H. C., Santee, M. L., Wu, D. L., Cuddy, D. T., Lay, R. R., Loo, M. S., Perun, V. S., Schwartz, M. J., Stek, P. C., Thurstans, R. P., Boyles, M. A., Chandra, K. M., Chavez, M. C., Chen, G.-S., Chudasama, B. V., Dodge, R., Fuller, R. A., Girard, M. A., Jiang, J. H., Jiang, Y., Knosp, B. W., Labelle, R. C., Lam, J. C., Lee, A. K., Miller, D., Oswald, J. E., Patel, N. C., Pukala, D. M., Quintero, O., Scaff, D. M., Vansnyder, W., Tope, M. C., Wagner, P. A., and Walch, M. J.: The Earth Observing System Microwave Limb Sounder (EOS MLS) on the Aura Satellite, IEEE T. Geosci. Remote, 44, 1075-1092, doi:10.1109/TGRS.2006.873771, 2006.

WMO: Scientific Assessment of Ozone Depletion: 2010, Global Ozone Research and Monitoring Project 52, 516 pp., World Meteorological Organisation, Geneva, Switzerland, 2011.

Zawodny, J. M. and McCormick, M. P.: Stratospheric Aerosol and Gas Experiment II measurements of the quasi-biennial oscillations in ozone and nitrogen dioxide, J. Geophys. Res., 96, 93719377, doi:10.1029/91JD00517, 1991. 